\title{
Investment Shocks and the Commodity Basis Spread $^{1}$
}

\author{
Fan Yang ${ }^{2}$
}

First Version: September 2009

This Version: July 3, 2011

\footnotetext{
${ }^{1}$ I am grateful to the members of my thesis committee: Frederico Belo, John Boyd, Bob Goldstein (chair), Jeremy Graveline, and Erzo G.J. Luttmer for many helpful discussions. I have also benefited from comments by Philip Bond, Pierre Collin-Dufresne, Nicolae Garleanu, Joao Gomes, Jun Li, Dmitry Livdan, Lars Lochstoer (WFA discussant), Thomas Mertens (FMA discussant), Nikolai Roussanov, Jacob Sagi, Motohiro Yogo, and Jianfeng Yu. I thank the seminar participants at several universities, the WFA 2011 Meeting, and the 2010 FMA Doctoral Students Consortium. I also would like to thank SAC Capital for the PhD Candidate Award for Outstanding Research in WFA 2011 and Joan Gieseke for excellent editorial assistance. All errors are my own.

${ }^{2}$ Department of Finance, Carlson School of Management, University of Minnesota, Suite 3-122, 321-19th Avenue South, Minneapolis MN, USA 55455, yang0946@umn. edu
} 


\title{
Investment Shocks and the Commodity Basis Spread
}

\begin{abstract}
I identify a "slope" factor in the cross section of commodity futures returns. Low-basis commodity futures have higher loadings on this factor than high-basis commodity futures. This slope factor and a level factor - an index of commodity futures - jointly explain most of the average excess returns of commodity futures portfolios sorted by basis. More importantly, I find that this factor is significantly correlated with investment shocks, which represent the technological progress in producing new capital. I investigate a competitive dynamic equilibrium model of commodity production to endogenize this correlation. The model reproduces the cross-sectional futures returns.
\end{abstract}




\section{Introduction}

This paper provides an empirical and theoretical analysis of the cross section of commodity futures average returns. Recent studies (e.g., Hong and Yogo (2009)) have shown that commodity futures returns are predictable, even at a monthly horizon. Futures contracts written on commodities with a low basis (that is, those commodities with a "low" ratio of futures price to spot price) tend to have higher expected returns than futures contracts written on commodities with a high basis. ${ }^{1}$ Hong and Yogo (2009) show this result in the aggregate time-series, and Gorton, Hayashi, and Rouwenhorst (GHR, 2008) observe this result in the cross section. Specifically, GHR form two commodity futures portfolios sorted by the commodity's basis and find a $10 \%$ annual return spread between low- and high-basis portfolios. I refer to this result as the "basis spread" throughout this paper. This basis spread is very similar to the return spread between high and low forward rate currencies in the foreign exchange market (Lustig and Verdelhan (2007)), in the sense that the high forward rate is equivalent to the low basis. Given the large economic magnitude of the basis spread, understanding its source is thus an important question.

To characterize the properties of commodity futures returns in the data, I split the commodity futures into five portfolios sorted by their basis. These portfolios are rebalanced at a monthly frequency. The futures of the low-basis commodities offer about $10 \%$ annual excess returns relative to the high-basis commodities, which is consistent with GHR's finding. Furthermore, I find that the average portfolio return is monotonically decreasing in basis. This is important evidence supporting that basis characterizes the risk of commodity futures.

Among the returns of these portfolios, I find large common movement, which can be summarized by two factors. These two factors are also highly correlated (higher than 95\%) with the first two principal components of these portfolios, which can capture a large fraction $(75 \%)$ of the total variance of these portfolios. The first factor is a commodity market factor, which is defined as equally weighted commodity futures excess returns across commodities and maturities. I test a commodity CAPM using the portfolios as test assets. Test results show that portfolios' risk exposure to this commodity market factor cannot explain the basis spread. ${ }^{2}$ In particular, all of the portfolios have basically the same loadings on the market factor, and thus cannot explain why excess returns vary dramatically with respect to basis. The second factor is a "slope" factor, which is defined as the return spread between low- and high-basis portfolios

\footnotetext{
${ }^{1}$ See, for example, Fama and French (1987).

${ }^{2}$ Hong and Yogo (2010) document (and I confirm here) substantial comovement in the futures returns across commodities and also provide evidence of an "aggregate commodity futures market premium."
} 
$\left(L M H_{F C}\right){ }^{3}$ The time-series asset pricing test results show that the commodity market and slope factors jointly explain the average returns of the commodity futures portfolios fairly well. In particular, the loadings on the slope factor are monotonically decreasing in basis, which suggests that the slope factor is a potential risk factor for commodity futures.

More importantly, I investigate the underlying risk of the slope factor and find that the factor is a negatively correlated with investment shocks, which represent the technological progress in producing new capital. Because investment shocks are associated with a negative price of risk (Papanikolaou (2010)), this novel finding supports a potential risk explanation of the positive risk premium of the slope factor.

To rationalize these empirical findings, I propose a production-based asset pricing model along the lines of Cochrane (1991) and Zhang (2005). In particular, I propose a model of many commodities which extends Kogan, Livdan, and Yaron (KLY, 2009) to reproduce the basis spread, the negative correlation between investment shocks and the slope factor, and many empirical tests. In the model, the homogeneous competitive firms produce commodities in the face of an exogenous demand curve. These producers optimize their investment decisions to maximize firm value.

The model rationalizes the basis spread by two key relationships. First, the model predicts that commodities with high investment producers offer higher futures returns. In the cross section of commodities, commodity producers with high investment today have more new capital to be installed, and hence face higher exposure to investment shocks. Because the capital of producers determines the supply and hence the prices of commodities, the same investment shock impacts the futures prices of commodities of high investment producers more than low investment ones in the cross section. In addition, the sign of loading on investment shocks is negative. This is because a positive investment shock represents technological progress in producing new capital; it increases the future supply and hence depreciates commodity prices. Therefore, the futures prices of commodities with high investment producers load more negatively on investment shocks. With the negative risk price of investment shocks, this explains why high investment producers are associated with high futures returns.

Second, the model also predicts that commodities with high investment producers have low-basis futures curves, the same as in KLY. Generally, a futures price can be decomposed into two parts: the expected spot price $(\mathrm{E}[P])$ and the risk premium $(-\operatorname{Cov}[M, P] / \mathrm{E}[M])$ as

$$
F=\frac{\mathrm{E}[M P]}{\mathrm{E}[M]}=\mathrm{E}[P]+\frac{\operatorname{Cov}[M, P]}{\mathrm{E}[M]} .
$$

\footnotetext{
${ }^{3}$ Lustig, Roussanov, and Verdelhan (2010) identify a similar "slope" factor to explain the forward rate puzzle in the foreign exchange market.
} 
From equation 1, it is easy to see that the low-basis or low-futures price can arise because of either the low expected spot price $(\mathrm{E}[P])$ or the more negative covariance $(\operatorname{Cov}[M, P])$ between the stochastic discount factor (SDF, $M$ ) and the spot price $(P)$. In KLY, a high investment rate predicts low future supply and hence a low expected spot price $(\mathrm{E}[P])$. My model inherits this channel. In addition, as discussed in the above paragraph, my model also relates commodity futures of high investment producers with a higher risk premium and hence a more negative covariance term $(\operatorname{Cov}[M, P])$. To summarize, my model relates commodities of high investment producers with low basis through these two channels.

Through these two key relationships, my model explains why investment shocks are negatively correlated with the basis spread as I find in the data and the positive basis spread. Quantitatively, the simulated return spread between the low- and high-basis futures portfolio matches the historical average $(10 \%)$. The simulated data also replicate the negative correlation between investment shocks and the slope factor as well as many empirical tests.

The model's prediction that high investment producers offer high futures returns does not contradict the fact that high investment rate firms have low stock returns. Kogan and Papanikolaou (2010a) investigate the stock price implications of investment shocks and find that investment shocks can explain the low stock returns associated with high investment firms. In my model, commodity prices and producers' stock prices have opposite signs in their exposures to investment shocks. Because a positive investment shock increases producers' investment efficiency and hence future supply, it increases producers' stock prices and decreases commodity prices. This may be one of the reasons why we observe a negative relationship between stock returns and commodity futures returns. My model can reconcile its implications with these empirical facts.

For parsimony, there is no inventory in my model. But adding many competitive inventory holders with a nonnegative inventory constraint as in Routledge, Seppi, and Spatt (RSS, 2000) does not change the main prediction of the model. The major part of the basis spread comes from the high excess return (about 10\% annually) of the low-basis portfolio. The futures curves of the commodities in this portfolio are strongly downward sloping. Their producers invest heavily, and hence expected spot prices are low relative to the current spot prices. With storage costs, inventory holders are reluctant to store any commodities in this portfolio and the inventories of these commodities are mostly "stocked out." Therefore, futures prices are only driven by production and consumption of commodities.

The rest of the paper proceeds as follows. Section 2 discusses the extant literature and clearly lays out the contributions of this paper with respect to that literature. Section 3 
discusses the data and reports the empirical analysis and results. In Section 4, I propose an investment-based model for pricing futures contracts of many commodities. Section 5 calibrates the model. Section 6 reports the model implications and comparisons. Section 7 concludes.

\section{Related literature}

This paper builds on a growing literature on commodity futures and investment-based asset pricing. To my knowledge, this is the first paper to explain cross-sectional futures returns without hedging pressure, and the first to rationalize cross-sectional futures returns with an investment-based model.

Classical theories explaining commodity futures return predictability date back to the hedging pressure hypothesis of Keynes (1923). This hypothesis argues that speculators who take long positions in futures demand a positive risk premium from producers, who short the futures to lock their future profits. This effect pushes down futures prices and thus lowers basis. Hirshleifer $(1988,1990)$ solves an equilibrium model with this hedging pressure story by assuming that speculators face fixed setup costs, and producers are not able to issue equity on their future cash flows. These market imperfections lead to a risk premium for bearing idiosyncratic production risk.

The empirical evidence of the hedging pressure theory is mixed. Bessembinder (1992) finds evidence to support the theory in Hirshleifer (1988). De Roon, Nijman, and Veld (2000) identify the futures premium from cross-market hedging pressure. In contrast, GHR reject the hedging pressure hypothesis in the cross section of commodities. Hong and Yogo (2010) also observe that the futures return predictability from hedging pressure, which is measured as the net short positions taken by commercials, is insignificant in aggregate time-series.

Other recent hedging pressure models include Acharya, Lochstoer, and Ramadorai (2010) and Etula (2009). Acharya et al. (2010) propose a limits-to-arbitrage production-based model with inventory to explain oil futures returns predictability from producers' default risk. Etula (2009) relates the commodity futures premia to the risk-bearing capacity of brokers and dealers with another limits-to-arbitrage model.

In contrast to these papers, my model is free of hedging pressure. Instead, my model features an investment shock, which is an important macroeconomic risk and well documented in macroeconomic literature (e.g., Greenwood, Hercowitz, and Krusell (1997, 2000); Fisher (2006); Justiniano, Primiceri, and Tambalotti (2010)). Stock return implications of investment shocks have been investigated by Papanikolaou (2010) and Kogan and Papanikolaou (2010a, 2010b). 
Structural models of commodities consist of two major categories: inventory- and productionbased models. Examples of inventory models include Deaton and Laroque $(1992,1996)$ and RSS. The key assumption of these models is a nonnegative inventory constraint, which distinguishes commodities from financial assets. Production-based models of commodities are widely developed as well, but mainly with risk-neutral agents to solve puzzles other than the risk premium. Examples include Litzenberger and Rabinowitz (1995), who explain the frequent backwardation in oil futures; Carlson, Khokher, and Titman (2007), who investigate futures price dynamics with an exhaustible constraint and capital adjustment costs of producers; and KLY. Casassus, Collin-Dufresne, and Routledge (2009) construct a general equilibrium model to explain the time-varying risk premium in oil futures.

This paper extends KLY to price cross-sectional commodity futures returns. KLY find a U-shaped volatility in oil futures and propose a production-based model that features an investment capacity constraint to explain this fact. I mainly add investment shocks to their model. Rather than focusing on volatility, this paper focuses on the average futures returns across commodities. Other differences in our models include separation of systematic and idiosyncratic demand shocks, and using standard quadratic capital adjustment costs rather than the investment capacity constraint.

Reduced-form models are also widely estimated in the commodity futures literature. Different from structural models, spot price dynamics and convenience yield are exogenous in these models. See, for example, Schwartz (1997), Schwartz and Smith (2000), Casassus and Collin-Dufresne (2005), and Trolle and Schwartz (2009).

This paper is also related to many other empirical papers in commodity futures. Gorton and Rouwenhorst (2005) and Erb and Harvey (2006) document many important empirical facts of commodity futures returns. Asness, Moskowitz, and Pedersen (2009) find a "value premium" and momentum effect in commodity futures. Tang and Xiong (2010) find that non-energy commodity futures are more correlated with oil around 2008.

This paper also extends the large growing literature on investment-based models to crosssectional returns of commodity futures. Examples of investment-based models of stock and bond returns are Cochrane (1991); Gomes, Kogan, and Zhang (2003); Carlson, Fisher, and Giammarino (2004); Zhang (2005); Liu, Whited, and Zhang (2009); Lettau and Wachter (2007); Gomes, Kogan, and Yogo (2009); Bazdresch, Belo, and Lin (2009); Lin (2010); and Kuehn and Schmid (2010), among others. 


\section{Empirical analysis}

In this section, I sort commodities by basis and split them into five portfolios by quantiles. The low-basis portfolio offers a return that is about $10 \%$ higher than that of the high-basis portfolio per annum. I call this $10 \%$ return spread the basis spread. Then I analyze the systematic risk of these portfolios within two samples. The full sample includes monthly close quotes of futures of maturities up to 12 months of 34 commodities from January 1970 to December 2008. To check the robustness of the empirical results, I also analyze a subsample of the same set of commodities from January 1985 to December 2008. Major empirical results are similar across samples.

\subsection{Data and variable definitions}

The commodity futures and spot price data are from the Commodity Research Bureau. The database includes a large panel of historical daily close quotes on futures and spot contracts traded across many commodity markets worldwide.

The sample starts in January 1970 and ends in December 2008. ${ }^{4}$ It includes monthly close quotes of futures contracts of maturities up to 12 months and spot contracts for a cross section of many commodities. The cross-sectional sample size ranges from 18 commodities in 1970 to 34 commodities in 2008 from four sectors: agriculture, energy, livestock, and metals. Futures contracts with maturities longer than 12 months are not liquidly traded and hence are excluded from the sample.

I define the futures excess return as the fully collateralized return of longing a futures contract. That is, at the time of signing a futures contract, the buyer has to deposit a cash amount that equals the present value of the futures price to eliminate counterparty risk. This cash amount, which is used as collateral, earns the risk-free rate. For commodity $i$, I denote $F_{i, t, T}$ as the futures price at time $t$ with maturity $T$. The futures excess return of longing this contract for one period is defined as

$$
R_{i, t, T}^{e}=\frac{F_{i, t+1, T-1}}{F_{i, t, T}}-1
$$

I exclude the return of holding a one-month futures to maturity in the sample, because it involves delivery of the underlying commodity.

I define the monthly basis as the log difference between the 12-month $\left(T_{2}=12\right)$ futures

\footnotetext{
${ }^{4}$ The database starts from 1959. In the early period, few commodities are traded. To ensure at least three commodities within a portfolio to diversify idiosyncratic risk, I compose my sample starting from 1970.
} 
price and the 1-month $\left(T_{1}=1\right)$ futures price divided by the difference in maturity as

$$
B_{i, t}=\frac{\log \left(F_{i, t, T_{2}}\right)-\log \left(F_{i, t, T_{1}}\right)}{T_{2}-T_{1}} .
$$

If the 1-month or 12-month futures price is not available, I use the price of the futures contract with the nearest maturity. The basis reported in the rest of this paper is annualized.

In addition, the spot price change is defined as

$$
\Delta P_{i, t}=\frac{P_{i, t+1}}{P_{i, t}}-1
$$

Because holding commodities involves other nonfinancial benefits and costs such as storage costs and convenience yield, measuring the return of buying and selling commodities on the spot market is not easy. Therefore, I use the term spot price change rather than return.

Table 1 reports the summary statistics of every individual commodity by sector in the sample. A commodity is in backwardation if its futures curve is downward sloping (basis is negative). Otherwise, it is in contango. Crude oil futures become available in 1983. As noted by Litzenberger and Rabinowitz (1995), its futures curve is in backwardation about $70 \%$ of the time. Gold and silver futures behave much closer to futures on financial assets rather than commodities. Their basis is close to the risk-free rate, and their futures curves have little probability of being in backwardation. Other commodities are associated with diversified average basis and frequency of backwardation. Historically, gasoline, propane, and live hogs futures have the highest Sharpe ratio (about 40\%).

\subsection{Portfolios sorted by basis}

I sort commodity futures contracts into five portfolios by basis with a monthly rebalance frequency. When constructing these portfolios, I first sort available commodities by basis at the end of month $t$ and then split them into portfolios by quantiles. At the end of the following month $t+1$, the futures contracts of these commodities are one month closer to their maturities. I compute the excess returns of these contracts from $t$ to the end of month $t+1$, and aggregate these excess returns within each portfolio using equal weights to construct the portfolio excess return of this month. I repeat this strategy month after month.

Table 2 reports the key statistics of futures excess return, spot price change, and basis of these five portfolios in percentages in the two samples. In the full sample, consistent with GHR's finding, the futures of low-basis commodities offer about $10 \%$ annual excess returns relative to high-basis commodities. Most of this return spread is due to the high excess return 
of the low-basis portfolio, since the high-basis portfolio has almost zero excess return in historical average. This fact suggests a highly profitable trading strategy of longing the low-basis portfolio, whose annual Sharpe ratio is $56 \%$. This Sharpe ratio is higher than holding futures of any individual commodities. More importantly, the portfolio excess return is monotonically decreasing in basis. This monotonic relationship supports my argument that basis is a potential risk characteristic in the cross section of commodities. The subsample from 1985 to 2008 has similar results.

The portfolio aggregate spot price change is increasing in basis. This is consistent with the empirical fact that the commodity spot price is mean-reverting (Deaton and Laroque (1992, 1996)).

The probability transition matrices of the five portfolios sorted by basis in both samples are reported in Table 3. Element $a_{i, j}$ in a matrix indicates the transition probability of a commodity from portfolio $i$ to $j$ in one month. The frequent transition of commodities across portfolios shows that the average return pattern is not because of some particular commodities but the characteristic - the basis of commodities.

\subsection{Factor models}

I introduce a commodity market factor and a $L M H_{F C}$ factor to explain the excess return of these portfolios. Multifactor models have been used to explain cross-sectional stock returns (Fama and French (1992)), bond returns (Fama and French (1993)), and forward returns in the foreign exchange market (Lustig, Roussanov, and Verdelhan (2010)).

First, I test a commodity CAPM. The market factor $(M k t)$ is defined as the equally weighted futures excess returns averaging across all commodities and maturities in the sample. Using the portfolios reported in Table 2 as test assets, I test this commodity CAPM with time-series regressions as

$$
R_{j, t}^{e}=\alpha_{j}+\beta_{j, M k t} M k t_{t}+\epsilon_{j, t}
$$

where $j=1$ to 5 and "L-H." The significance of abnormal return $\left(\alpha_{j}\right)$ tests whether the model can explain the excess return of portfolio $j$.

The tests reject the commodity CAPM. The results of time-series regression tests of the commodity CAPM are reported in Table 4 . The $t$-stats of the abnormal returns $\left(\alpha_{j}\right)$ of several portfolios are statistically significantly different from zero. In particular, the commodity market factor can explain only about $1 \%$ of the return of the $\mathrm{L}-\mathrm{H}$ portfolio, given that the average return is $10.26 \%$ and the abnormal return is $9.16 \%$ controlled by the commodity market factor. 
The commodity CAPM cannot explain the return of the L-H portfolio in the subsample from 1985 to 2008 as well.

Then, I introduce a second factor $\left(L M H_{C F}\right)$, which is defined as the return of the L-H portfolio. I also use time-series regressions to test this two-factor model as

$$
R_{j, t}^{e}=\alpha_{j}+\beta_{j, M k t} M k t_{t}+\beta_{j, L M H_{C F}} L M H_{C F, t}+\epsilon_{j, t},
$$

where $j=1$ to 5 .

The time-series test results are reported in Panel A of Table 5. All the abnormal returns $\left(\alpha_{j}\right)$ of these five portfolios are statistically insignificant. The two-factor model passes these time-series regression tests both in the full sample and in the subsample from 1985 to 2008. The alphas of the subsample are even less in absolute values. More importantly, the portfolio loading on the $L M H_{C F}$ factor $\left(\beta_{j, L M H_{C F}}\right)$ is monotonically decreasing in basis. These statistics show that the $L M H_{C F}$ factor accounts for an important part of the comovement among commodity futures returns.

\subsection{Price of risk}

Besides the time-series regression tests, the two-factor model also passes the cross-sectional asset pricing tests. I estimate the price of risk and factor loadings of the commodity market $(M k t)$ and $L M H_{C F}$ factors using both General Method of Moments (GMM, Hansen (1982)) and the Fama-MacBeth (FMB) method (Fama and MacBeth (1973)). Panel B of Table 5 reports the estimation results.

In linear factor models, I specify the stochastic discount factor (SDF) as a linear function of factors $\left(f_{t+1}\right)$ as

$$
M_{t+1}=1-b^{\prime}\left(f_{t+1}-\bar{f}\right),
$$

where $b$ represents the vector of factor loadings. With a no-arbitrage condition, the excess returns of portfolio $j$ satisfy investors' Euler equation,

$$
\mathrm{E}_{t}\left[M_{t+1} R_{j, t+1}^{e}\right]=0 .
$$

I use these equations from many portfolios as moment conditions of GMM to test the twofactor model and estimate factor loadings $(b)$. The price of risk $(\lambda)$ can be computed from factor loadings using

$$
\lambda=\Sigma_{f} b,
$$


where factor covariance matrix, $\Sigma_{f}=\mathrm{E}\left[\left(f_{t}-\bar{f}\right)\left(f_{t}-\bar{f}\right)^{\prime}\right]$. The standard errors of estimated $\hat{\lambda}$ are computed using the delta method.

Intuitively, the FMB method tests the hypothesis that the cross-sectional differences in asset returns are due to the cross-sectional differences in asset risk exposure. FMB consists of two steps. First, I regress the time-series of the excess returns of portfolio $j$ on the two factors to estimate the vector of risk exposure $\left(\beta_{j}\right)$ as

$$
R_{j, t}^{e}=\alpha_{j}+\beta_{j}^{\prime} f_{t}+\epsilon_{j, t}
$$

Second, I regress the portfolio average excess returns $\left(\mathrm{E}\left[R_{j, t}^{e}\right]\right)$ on its risk exposure $\left(\beta_{j}\right)$ in the cross section of portfolios as

$$
\mathrm{E}\left[R_{j, t}^{e}\right]=a+\lambda^{\prime} \beta_{j}+e_{j}
$$

The slope of the cross-sectional regression is the risk price $(\lambda)$ of factors. And the intercept $(a)$ represents the average abnormal return across portfolios. If $a$ is different from zero, the model fails to explain the returns of portfolios. The $\chi^{2}$-test is used to test whether this intercept $(a)$ is statistically significant.

The two-factor model passes all these cross-sectional tests. Estimation results of first-stage $\left(\mathrm{GMM}_{1}\right)$, second-stage GMM $\left(\mathrm{GMM}_{2}\right)$, and FMB method are reported in Panel B of Table 5. For the full sample, the last row reports the average excess returns of the commodity market factor (6.01\% per annum) and the $L M H_{C F}$ factor (10.26\% per annum). The estimated price of risk ( $\lambda_{M k t}$ and $\lambda_{L M H_{F C}}$ ) using all methods is very close to the average excess returns of the two factors. Theoretically, when factors are excess returns, the price of risk should equal their time-series averages. This no-arbitrage condition holds for the two factors among these portfolios. Both the price of risk $(\lambda)$ and factor loadings $(b)$ are significantly different from zero under both methods. The significance of $\lambda$ indicates that both $M k t$ and $L M H_{F C}$ factors are priced. The $t$-stats of $b$ show that both factors help to price these portfolios (Cochrane (2005)). Meanwhile, the $R^{2}$ of the cross-sectional regressions are about $83 \%$; and the root mean square error (RMSE), which approximates the average alpha of these portfolios, is about $1.6 \%$ per annum. The $p$-values of $\chi^{2}$-tests are about $25 \%$ across all three tests. The two-factor model passes all these cross-sectional tests.

The two-factor model performs even better in the subsample from 1985 to 2008. The test results of this subsample are reported on the right side of Table 5 . The $R^{2}$ is around $95 \%$, which is higher than the full sample. The RMSE is less than $1 \%$. And the $p$-value of the $\chi^{2}$-test cannot reject the two-factor model. As there are more commodities and more futures contracts 
being traded in the later part of the sample, idiosyncratic risk can be more well diversified. The commodity futures market becomes more integrated, and the commodity futures tend to comove more. Therefore, the two-factor model captures the comovement of these portfolios better.

\subsection{Principal components as factors}

I analyze the principal components of the portfolio excess returns and find that the second principal component is crucial to explain the basis spread.

Table 6 reports the results of the principal component analysis. Panel A reports the loadings of every portfolio on five principal components and the percentage of the total variance of these portfolios that can be explained by each principal component. Among these five principal components, the first two account for almost $75 \%$ of the total variance of these portfolios. The loadings on the first principal component are similar across portfolios, so that it is a level factor. I find that it is $99.7 \%$ correlated with the commodity market factor. The loading on the second principal component is monotonically decreasing in basis. Therefore, it is a slope factor. The correlation between the slope and $L M H_{C F}$ factors is $95.5 \%$. The subsample from 1985 to 2008 yields similar results, which are reported in Panel B of Table 6. The correlation between the $M k t$ and level factors is $99.5 \%$, and the correlation between the $L M H_{C F}$ and slope factors is $95.4 \%$ in the subsample. The two factors I proposed in the previous section are basically the first two principal components of these portfolios.

I provide further empirical evidence to support that the slope or $L M H_{C F}$ factor is a good candidate for the risk factor. I calculate the covariances between the excess returns of five portfolios and each principal component and compare them with the average excess return of five portfolios following Cochrane and Piazzesi (2005). The results are reported in Figure 1. Among the five principal components, only the covariance of the second one (slope) and portfolio returns is monotonically decreasing in basis, and it shares the same shape as the average excess returns of these portfolios. Therefore, the second principal component (slope) or $L M H_{C F}$ factor is important to explain these portfolio returns.

Using the five portfolios sorted by basis, I test an alternative two-factor model. The two factors are the level and slope factors. Both the time-series and cross-sectional test results are reported in Table 7. Similar to the $L M H_{F C}$ factor, the slope factor is significantly priced and has a risk price of $7.23 \%$ in the full sample and $4.88 \%$ in the subsample from 1985 to 2008 . This two-factor model using the first two principal components as factors also passes all the time-series and cross-sectional tests in both samples. 


\subsection{Beta-sorted portfolios}

The difference in portfolio average excess returns is not because of the differences in the characteristics of these portfolios but rather because of the difference in their risk exposure. To show the robustness of $L M H_{F C}$ as a potential risk factor, other than forming portfolios sorted by basis, I also form five portfolios sorted by each commodity's futures risk exposure to the $L M H_{C F}$ factor to verify that $L M H_{C F}$ is a good risk factor candidate. The key statistics of these five portfolios in both the full sample and the subsample from 1985 to 2008 are reported in Panels A and B correspondingly in Table 8.

I describe the process of forming these portfolios as follows. At the end of month $t$, first I aggregate 12-month pre-formation futures excess returns across maturities for every commodity. I compute the pre-formation risk exposure $(\beta)$ to the $L M H_{C F}$ factors of a commodity by regressing these futures excess returns on the commodity market and $L M H_{C F}$ factors. Then I sort commodities by their pre-formation $\beta$ to $L M H_{C F}$ factors and split them into five portfolios by quantiles. I repeat this process month after month. I compute the portfolio excess returns as the equally weighted averages across the commodity futures excess returns across commodities and maturities in the portfolio.

By comparing Table 8 and Table 2, I find that the patterns of expected returns, volatilities, and betas of basis-sorted portfolios and beta-sorted portfolios are basically the same. The basis of commodities is monotonically increasing in their risk exposure $(\beta)$ to the $L M H_{C F}$ factor. This indicates that basis and the risk exposure $(\beta)$ to the $L M H_{C F}$ factor are interrelated, so that the basis of commodities characterizes the risk of their futures contracts. I also report the average excess returns (Mean) and volatility (Std) of the portfolios sorted by pre-formation $\beta$. Even though the expected returns of these portfolios are not strictly monotonically decreasing in pre-formation $\beta$, H-L portfolios still offer an annual average excess return $6.57 \%$ in the full sample and $5.06 \%$ in the subsample. Commodity futures that are more correlated with the $L M H_{C F}$ factor have higher returns. The post-formation $\beta$ to $L M H_{C F}$ is estimated by regressing beta-sorted portfolio excess returns on the two factors. It is monotonically increasing in pre-formation $\beta$. These statistics of beta-sorted portfolios provide empirical evidence to support that the covariance structure between commodity futures returns and the $L M H_{C F}$ factor is a potential explanation for why low-basis commodities offer higher futures returns than high-basis commodities historically. 


\subsection{Investment shocks and the basis spread}

Previous sections empirically identify $L M H_{C F}$ as a potential candidate for the risk factor. I argue that it is a risk premium that compensates investors for bearing investment shocks. I also find empirical support for this argument.

Investment shocks represent the technological progress in producing new capital. Following Kogan and Papanikolaou (2010a), I use two empirical proxies of investment shocks to investigate their relationship with the basis spread. ${ }^{5}$ The first proxy is the $I M C$ factor, which is defined as the excess returns of longing stocks of investment good producers and shorting stocks of consumption good producers. The other one is the relative price of investment goods as in Greenwood, Hercowitz, and Krusell (1997, 2000). The second measure of investment shocks $\left(z_{t}^{\xi}\right)$ is computed as the innovations of the relative price of investment goods $\left(\xi_{t}\right)$,

$$
\log \xi_{t}=a_{0} t+a_{1} t \mathbf{1}_{\{t>1982\}}+\rho \log \xi_{t-1}-z_{t}^{\xi} .
$$

A positive investment shock $\left(z_{t}^{\xi}>0\right)$ represents the technological progress in producing new capital, or equivalently a lower price for investment goods $\left(\xi_{t}\right)$. The growth rate of the investment goods price is allowed to differ before and after 1982 because it experiences an abrupt increase in its average rate of decline in 1982 as noted in Fisher (2006) and Justiniano et al. (2010).

Table 9 reports the risk exposure (univariate betas) of portfolios to the commodity market factor $(M k t)$ and the two measures of investment shocks (IMC and $z^{\xi}$ ). The excess returns of portfolios are annualized to smooth the seasonality of commodities. Panel A reports the portfolio risk exposure for the full sample. Panel B reports the portfolio risk exposure for the subsample from 1985 to 2008 . The market betas $\left(\operatorname{Cov}\left(R_{j}^{e}, R_{M k t}^{e}\right) / \sigma_{M k t}^{2}\right)$ are very similar across portfolios sorted by basis. Hence, commodity market risk is not a good candidate for explaining the basis spread, as we noted in previous sections.

The univariate betas of portfolios on the $I M C$ factor are monotonically increasing in basis in the full sample. The L-H portfolio has a significant negative beta to the $I M C$ factor. Its univariate beta $\operatorname{Cov}\left(R_{j}^{e}, R_{I M C}^{e}\right) / \sigma_{I M C}^{2}=-0.52$ with a $t$-stat of -3.63 . The correlation between the annual $I M C$ and $L M H_{F C}$ factors is $-30 \%$. And the correlation between the annual $I M C$ and slope factors is $-32 \%$. Because Papanikolaou (2010) finds that investment shocks $(I M C)$ are associated with a negative price of risk, this explains why the $L M H_{F C}$ or slope factors are associated with a positive risk premium. The monotonic increasing univariate beta suggests that investment shocks can be the underlying risk that drives the difference in

\footnotetext{
${ }^{5}$ I thank Dimitris Papanikolaou for sharing the data for investment shocks.
} 
average returns of these portfolios sorted by basis. As a robustness check, in the subsample from 1985 to 2008, the L-H portfolio also has a significantly negative loading on the $I M C$ factor $\left(\operatorname{Cov}\left(R_{j}^{e}, R_{I M C}^{e}\right) / \sigma_{I M C}^{2}=-0.43\right.$ with a $t$-stat of -2.53$)$. The univariate beta to the $I M C$ factor is basically increasing in basis.

When I use the innovations of the relative price of investment goods $\left(z^{\xi}\right)$ as the proxy for investment shocks, the patterns are basically the same. In the full sample, the univariate beta to $z^{\xi}$ is monotonically increasing in basis for portfolios $2,3,4$, and high. The low-basis portfolio has a positive beta to this shock in the full sample because it is positively correlated with this proxy from 1970 to 1976. If we drop this initial period, the univariate beta of the low-basis portfolio decreases to -1.28. As in the subsample from 1985 to 2008, this negative relationship between risk exposure and basis can be observed in most of the portfolios.

To summarize, I find direct empirical evidence to link the basis spread with investment shocks. The excess return of the low-basis portfolio relative to the high-basis portfolio is negatively correlated with investment shocks. Because investment shocks have a negative price of risk, they help explain the higher futures return of the low-basis portfolio.

\section{Model}

In this section, I construct an investment-based dynamic equilibrium model extending KLY to endogenize the fact that the $L M H_{F C}$ factor is negatively related to investment shocks as documented in Section 3.7. Through this channel, the model is able to replicate the basis spread and many other empirical facts.

\subsection{Setup}

In a competitive commodity production economy, there are $N$ different commodities. I assume that commodities are nonstorable and mutually nonsubstitutable. ${ }^{6}$ Each commodity has a large number of identical producers such that we can reduce their complex behavior into a single representative producer problem. The production technology follows a Cobb-Douglas production function as

$$
Q_{j, t}^{S}=A K_{j, t}^{\alpha}
$$

Without loss of generality, I assume production is deterministic $A=1$ and constant returns to scale $\alpha=1$. Since this paper focuses on commodity price implications, we can combine the

\footnotetext{
${ }^{6}$ Including competitive inventory holders as in RSS does not change the model's prediction on the basis spread, as I argue in the introduction.
} 
productivity and demand shocks of a commodity into a single demand shock, whereas capital share $\alpha$ and price elasticity of demand $\eta$ can be combined as a single parameter in the social planner's problem.

Following Fisher (2006), the capital of this producer accumulates as

$$
K_{j, t+1}=(1-\delta) K_{j, t}+Y_{t} I_{j, t}
$$

$Y_{t}$ represents the level of investment-specific technology. It is an aggregate shock that impacts the real investment of all commodity producers $(j=1,2, \ldots N)$.

Firms own capital and produce commodities using the above technology. A producer's profit is generated from the revenue of selling its output commodity deducted by the costs of investment:

$$
\pi_{j, t}=P_{j, t} Q_{j, t}^{S}-I_{j, t}-S\left(I_{j, t}, K_{j, t}\right)
$$

where

$$
S(I, K)=\frac{\theta}{2}\left(\frac{I}{K}\right)^{2} K
$$

is the standard quadratic capital adjustment $\operatorname{cost}(\theta>0)$. Another investment friction includes investment irreversibility $\left(I_{j, t} \geq 0\right)$, which is also standard in the investment-based literature.

In a competitive equilibrium, producers take commodity spot prices as given and make investment decisions to maximize firm value subject to the irreversibility constraint on real investment. The firm value of a producer of commodity $j$ is defined as the present value of all future profits discounted by $\operatorname{SDF}\left(M_{t}\right)$ as

$$
V_{j, 0}=\max _{I_{t} \geq 0} \mathrm{E}_{0}\left[\sum_{t=0}^{\infty}\left(\prod_{u=0}^{t} M_{u}\right) \pi_{j, t}\right] .
$$

The demand for a commodity is exogenous. A commodity faces two types of demand shocks: systematic demand shock $\left(X_{t}\right)$ and idiosyncratic demand shock $\left(Z_{t}\right)$. The inverse demand function of commodity $j$ is

$$
P_{j, t}=P\left(X_{t}, Z_{j, t}, Q_{j, t}^{D}\right)=\left(\frac{X_{t} Z_{j, t}}{Q_{j, t}^{D}}\right)^{\eta},
$$

where $\eta$ measures the price elasticity of demand. The market clearing condition is

$$
Q_{j, t}^{S}=Q_{j, t}^{D}
$$


There are three exogenous shocks in this economy: aggregate demand shocks $\left(X_{t}\right)$, idiosyncratic demand shocks $\left(Z_{j, t}\right)$, and investment shocks $\left(Y_{t}\right)$. Aggregate demand shocks drive the common movement of demand across commodities. Idiosyncratic demand shocks introduce heterogeneity across commodities in order to generate cross-sectional returns. Investment shocks is an aggregate shock, which is crucial to replicate the basis spread. To simplify the model solution, I assume log demand shocks follow random walk processes. Log investment shocks follow an AR(1) process as in Justiniano et al. (2010):

$$
\begin{aligned}
\log X_{t+1} & =\log X_{t}+g_{x}+\sigma_{x} e_{t+1} \\
\log Z_{j, t+1} & =\log Z_{j, t}+\sigma_{z} \epsilon_{j, t+1}, \\
\log Y_{t+1} & =\rho_{y} \log Y_{t}+\sigma_{y} u_{t+1}
\end{aligned}
$$

Following Zhang (2005), the SDF is exogenous. This is a reduced-form way to model the consumer's problem. It is common in the literature of studying cross-sectional stock returns. Deviating from the conditional CAPM framework (as in Zhang (2005)), my model is a twofactor model with constant prices of risk more similar to Eisfeldt and Papanikolaou (2010) and Kogan and Papanikolaou (2010a, 2010b). Both aggregate demand shocks and investment shocks are priced in this economy. I parameterize the SDF as

$$
M_{t+1}=\frac{1}{\phi_{t}} \exp \left[-r_{f}-\gamma_{x} \sigma_{x} e_{t+1}-\gamma_{y}\left(\log Y_{t+1}-\log Y_{t}\right)\right]
$$

where

$$
\phi_{t}=\mathrm{E}_{t}\left[\exp \left[-\gamma_{x} \sigma_{x} e_{t+1}-\gamma_{y}\left(\log Y_{t+1}-\log Y_{t}\right)\right]\right]
$$

is a compensator so that the SDF satisfies the no-arbitrage condition $\mathrm{E}_{t}\left[M_{t+1}\right]=e^{-r_{f}}$ over all states of the economy. ${ }^{7}$

\section{2 $\quad$ Futures price}

The futures price is defined as the risk-neutral expected spot price. Buying a futures contract with maturity $T$ written on commodity $j$ costs zero at time $t$. The payoff at maturity is $P_{j, t+T}-F_{j, t, T}$. Therefore,

$$
0=\mathrm{E}_{t}\left[\left(\prod_{u=t+1}^{t+T} M_{u}\right)\left(P_{j, t+T}-F_{j, t, T}\right)\right] .
$$

\footnotetext{
${ }^{7}$ Even though $\phi_{t}$ has a close-form solution, it has to be computed numerically to precisely compensate for the SDF, since we apply the SDF numerically when solving the optimal investment rate, spot, and futures prices.
} 
I rewrite the above equation in its recursive form,

$$
F_{j, t, T}=e^{r_{f}} \mathrm{E}_{t}\left[M_{t+1} F_{j, t+1, T-1}\right] .
$$

The boundary condition is

$$
F_{j, t, 0}=P_{j, t},
$$

because the futures price converges to its spot price as the contract approaches maturity. First, I solve for market clearing spot price dynamics. Then, I compute the above expectation numerically to solve for futures prices with many maturities over all economic states.

\subsection{Spot price dynamics and risk exposure}

Because futures contracts are derivatives written on the spot price (Equation 25), spot price dynamics determine the risk exposure of futures contracts. From the inverse demand function (Equation 18), market clearing condition (Equation 19), production technology (Equation 13), and dynamics of exogenous shocks (Equations 20, 21, and 22), I derive the spot price dynamics as

$$
\log P_{j, t+1}=\log P_{j, t}+g_{j, t}^{P}+\eta \sigma_{x} e_{t+1}+\eta \sigma_{z} \epsilon_{j, t+1}
$$

where $g_{j, t}^{P}=-\eta \log \left(1-\delta+Y_{t} i_{j, t}^{*}\right)+\eta g_{x}$ is the growth rate of the spot price and $i_{j, t}^{*}$ is the optimal investment rate. Both aggregate and idiosyncratic demand shocks $\left(e_{t+1}\right.$ and $\left.\epsilon_{j, t+1}\right)$ are short-run risk. Investment shock $\left(Y_{t}\right)$ impacts the growth rate of the spot price. Therefore, the investment shock is a long-run risk (Bansal and Yaron (2004)) in this model. It is priced under the Epstein-Zin preference. The risk loading on investment shocks is approximately $-\eta i_{j, t}^{*}$, which is time-varying and endogenous.

Spot price dynamics is useful in interpreting how low basis predicts high futures returns through the investment channel. When the representative producer of commodity $j$ makes a lot of investment, $i_{j, t}^{*}$ is high. The growth rate of the spot price $\left(g_{j, t}^{P}\right)$ is low because it is a decreasing function of the investment rate. Hence, the expected spot price as well as basis is low. Meanwhile, under high investment $\left(i_{j, t}^{*}\right)$, the growth rate of the spot price $\left(g_{j, t}^{P}\right)$ faces more negative exposure $\left(-\eta i_{j, t}^{*}\right)$ to investment shocks $\left(Y_{t}\right)$. Therefore, the expected futures return is high with the assumption that investment shocks are associated with a negative price of risk. The idiosyncratic demand shock $\left(\epsilon_{j, t+1}\right)$ helps generate the cross section. This explains why low basis is associated with high futures returns in the cross section of commodities. 
This spot price dynamics is very close to the one in KLY. Deviating from theirs, I introduce investment shocks $\left(Y_{t}\right)$ into the dynamics. Futures contracts are exposed to investment shocks through the investment channel.

\subsection{Social planner's problem}

Following Lucas and Prescott (1971), I solve the competitive equilibrium allocation by solving an equivalent social planner's problem. I suppress the subscript $j$ for notational simplicity. The social surplus is defined as

$$
S S_{t}=\int_{0}^{Q_{t}} P\left(X_{t}, Z_{t}, q\right) d q=\frac{1}{1-\eta} X_{t}^{\eta} Z_{t}^{\eta} Q_{t}^{1-\eta}
$$

The social planner chooses investment to maximize the present value of social surplus net of investment costs. The Bellman equation for the social planner is

$$
S V_{t}=\max _{I_{t} \geq 0}\left[S S_{t}-I_{t}-S\left(I_{t}, K_{t}\right)+\mathrm{E}_{t}\left[M_{t+1} S V_{t+1}\right]\right] .
$$

I detrend this model in Section 8.2 of the Appendix and use the value function iteration to solve for the optimal investment and spot price dynamics.

\section{Calibration}

I calibrate my model at a monthly frequency with parameters from either existing literature or key moments of commodity futures.

The choices of parameters are reported in Table 10. The monthly capital depreciation rate is set as $\delta=0.01$ from the empirical estimation in Cooper and Haltiwanger (2000). The literature offers a wide choice of price elasticity of demand for many types of goods. Caballero and Pindyck (1996) and Zhang (2005) choose $\eta=0.5$ for consumption goods. Carlson, Khokher, and Titman (2007) pick $\eta=1$ for crude oil. KLY calibrate oil futures to get $\eta=3.15$ using the Simulated Method of Moments. I pick price elasticity of aggregate commodity demand $\eta=3$. The slope parameter of monthly capital adjustment costs is set as $\theta=12$ following Bazdresch, Belo, and Lin (2009). I set the monthly persistence and volatility of investment shocks as $\rho_{y}=0.92$ and $\sigma_{y}=0.03$ from the Bayesian estimates from Justiniano et al. (2010). Volatility of aggregate demand shock $\sigma_{x}=0.008$ is chosen to match commodity futures market volatility. Volatility of idiosyncratic demand shock $\sigma_{z}=0.06$ is chosen to match portfolio volatility. Following RSS and Eisfeldt and Papanikolaou (2010), I set the aggregate demand growth rate to be $\mu_{x}=0.5 \% / 12$ and the monthly risk-free rate to be $r_{f}=4 \% / 12$. It is a 
little higher than the historical mean (3\%). This helps the convergence of the value function iteration. The choices of the aggregate demand growth rate and the risk-free rate do not affect the commodity futures excess returns directly. Finally, I set the prices of risk as $\gamma_{x}=1$ and $\gamma_{y}=-12$. The first helps match the commodity futures market premium, whereas the latter helps match the difference in average returns between the low- and high-basis portfolios.

I solve the model using the value function iteration. The value and major policy functions are reported in Figure 2. After detrending, state variables of the model reduce to detrended capital $\left(\hat{K}_{t}\right)$ and investment shocks $\left(Y_{t}\right)$. The upper left panel reports the value function. It is increasing in detrended capital and investment shocks. The upper right panel reports the optimal investment rate. Because of the investment irreversibility constraint, the investment rate is nonnegative. Inherited from the standard investment-based model, the investment rate is decreasing in detrended capital. In addition, because a positive investment shock represents higher efficiency in investment, producers invest more given the same capital level. Hence, the dotted curve is above the dashed curve.

Basis is decreasing in investment. The lower left panel reports the basis as a function of the state variables. Given the policy functions of futures price $F\left(T, \hat{K}_{t}, Y_{t}\right)$ and spot price $P\left(\hat{K}_{t}, Y_{t}\right)$, basis is computed as

$$
B\left(\hat{K}_{t}, Y_{t}\right)=\log \frac{F\left(T, \hat{K}_{t}, Y_{t}\right)}{P\left(\hat{K}_{t}, Y_{t}\right)},
$$

where $T=12$ months. Figure 2 shows that basis is increasing in detrended capital and decreasing in investment shocks. Because of the negative relationship between the optimal investment rate and detrended capital, as shown in the upper right panel, basis is a decreasing function of the investment rate. This is one of the two crucial relationships in generating the basis spread.

The second crucial relationship is that the futures expected return is positively related to investment. The lower right panel reports the expected excess return of longing 12-month futures for one month. Longing futures with other maturities for one month has an expected return of the same shape. With the policy functions of futures price $F\left(T, \hat{K}_{t}, Y_{t}\right)$, the expected futures excess return is computed as

$$
\mu_{F}\left(T, \hat{K}_{t}, Y_{t}\right)=\frac{\mathrm{E}_{t}\left[F\left(T-1, \hat{K}_{t+1}, Y_{t+1}\right)\right]}{F\left(T, \hat{K}_{t}, Y_{t}\right)}-1
$$

The expectation is computed numerically. As shown in the figure, the expected futures excess return is negatively related to detrended capital, which is negatively related to investment. 
Therefore, high investment predicts high futures returns. This is another key relationship of the model.

Through endogenizing these two crucial relationships, my model explains the basis spread qualitatively. In the next section, I show that my model can also quantitatively replicate the basis spread.

\section{Model implications and discussion}

I use Monte Carlo simulation to investigate the important moments predicted by the model. To neutralize the effect of initial conditions, I first simulate 35 commodities for 1,000 years. Then I take the end values of the cross section of state variables from this simulation as the initial states of the economy. Using these initial states, I create 1,000 artificial panels, each of which includes monthly observations of 39 years of futures prices with maturities up to 12 months of 35 commodities. The same empirical analysis is applied to these simulated panel data to directly compare them with the results from the real ones. Key statistics (e.g., estimates and $t$-stats) are averages of the corresponding ones across these panels. As reported in Panel A in Table 11, the model replicates the commodity market average excess returns $\left(\mathrm{E}\left[R^{e}\right]=6 \%\right)$, volatility $\left(\sigma\left[R^{e}\right]=13 \%\right)$, and Sharpe ratio (45\%) reasonably well.

\subsection{Basis-sorted portfolios}

In this section, I investigate the model implications of the basis spread.

The benchmark model reproduces the basis spread (10\%) quantitatively with my choice of parameters. Panel B in Table 11 compares the average excess returns $\left(\mathrm{E}\left[R^{e}\right]\right)$, volatilities $\left(\sigma\left[R^{e}\right]\right)$, and Sharpe ratios of these portfolios formed in both real data and simulated data. The portfolio average excess return is monotonically decreasing in basis, and longing the low-basis portfolio earns a return that is about $10 \%$ higher than the high-basis portfolio historically. The model reproduces these facts fairly well.

To show the importance of investment shocks in generating the basis spread, I also simulate a model with a zero risk price of investment shocks $\left(\gamma_{y}=0\right)$. The results are reported on the right side of Panel B in Table 11. When investment shocks are not priced, most portfolios have insignificant excess returns. In particular, the L-H portfolio has an average return close to zero. Therefore, investment shocks with a negative risk price is the key in the benchmark model to reproducing the basis spread.

Different from the U-shaped volatility in real data and KLY, the model-predicted futures portfolio volatility $\left(\sigma\left[R^{e}\right]\right)$ is monotonically increasing in basis. This is because of the quadratic 
capital adjustment costs, which are different from the capacity constraint in KLY. Inherited from KLY, the optimal investment of producers in my model smooths demand shocks. A positive demand shock raises the spot price, which induces the producers to invest. By investing, the producer increases the supply of a commodity and thus lowers the spot price. Therefore, this optimal response tends to smooth spot price volatility. However, volatility smoothing is limited when investment is restricted. Because the quadratic capital adjustment costs are less restricted than the capacity constraint, the smooth effect in my model is more effective than KLY when investment is high or basis is low, which leads to a less volatile low-basis portfolio.

However, adding an inventory helps replicate the U-shaped volatility in my model. This is because inventory (as in RSS) can also smooth demand shocks but in the opposite way of producers' investment. A positive demand shock raises the spot price, which induces inventory holders to sell. Hence, the supply of commodities from inventories raises and hence depreciates the spot price. This smooth effect is restricted by a nonnegative inventory constraint. Therefore, an inventory model predicts high futures volatility when the spot price is high or basis is low. If we model production and inventory jointly, the investment and inventory constraints generate high volatility when basis is either low or high. This provides another explanation for the U-shaped volatility in commodity futures that is different from that in KLY.

\subsection{Tests of factor models in simulated data}

The model replicates the failure of commodity CAPM and the success of the two-factor model in explaining the portfolios sorted in basis. Table 12 replicates Tables 4 and 5 with simulated data.

Using the portfolios formed with simulated data in each panel, I test the commodity CAPM and the two-factor model with the commodity market $(M k t)$ and $L M H_{F C}$ factors. Panel A of Table 12 reports the results.

The commodity CAPM is also rejected in the simulated data as in historical data. Similar to what was reported in Table 4, the L-H portfolio has more than $9 \%$ excess returns with a $t$-stat greater than 2. And its exposure to the commodity market factor is almost zero. Therefore, as in the real data, the risk exposure to commodity market risk cannot explain the basis spread in simulated data as well.

The two-factor model passes the time-series tests using simulated portfolios as test assets. We can compare the results reported in the middle section of Panel A in Table 12 with the left section of Panel A in Table 5. The abnormal returns (alpha) of these portfolios are almost zero with insignificant $t$-stats. The loadings of portfolios on the market factor are close to one. 
More importantly, the risk exposure to the $L M H_{F C}$ is monotonically decreasing in basis. The model replicates all these patterns that are found in historical data.

The upper left panel of Table 12 reports the portfolio betas to the innovations of two systematic shocks $\left(\Delta \log X_{t}\right.$ and $\left.\Delta \log Y_{t}\right)$ in the model. The beta to investment shocks $\left(\Delta \log Y_{t}\right)$ is monotonically increasing in basis. This pattern is also found in real data as reported in Table 9. In particular, the L-H portfolio has a significantly negative beta to investment shocks. Therefore, the model endogenizes this cross-sectional negative correlation between investment shocks and the basis spread as in historical data. This is the key correlation that the model can generate the basis spread.

The exposure to the aggregate demand shock $\left(\Delta \log X_{t}\right)$ is monotonically increasing in basis. This is similar to the pattern of portfolio volatilities and because of the smooth effect discussed in the previous section.

Panel B of Table 12 reports the cross-sectional tests of the two-factor model in simulated data. In comparison with Panel $\mathrm{B}$ of Table 5, the two factors are significantly priced in simulated data as well. The estimated price of risk of the $L M H_{F C}$ factor $\left(\lambda_{L M H_{F C}}\right)$ using three methods (first step GMM, second step GMM, and FMB) is close to the average excess return of this factor. This no-arbitrage condition holds for the two factors among these portfolios. Both the price of risk $(\lambda)$ and factor loadings $(b)$ are significantly different from zero under both methods as in the data. Similarly, the significance of $\lambda$ indicates that both the $M k t$ and $L M H_{F C}$ factors are priced. The $t$-stats of $b$ show that both factors help to price these portfolios. Meanwhile, the $R^{2}$ of the cross-sectional regressions is about $60 \%$; and the RMSE, which approximates the average alpha of these portfolios, is about $2.2 \%$ per annum. The $p$ values of $\chi^{2}$-tests are about $40 \%$ across all three tests. Using these simulated portfolios as test assets, the two-factor model also passes all these cross-sectional tests, the same as in historical data.

\subsection{Term structure of the basis spread}

The model can also replicate the term structure of the basis spread reasonably well. Figure 3 compares the basis spreads across many maturities from historical and simulated data.

I form portfolios double-sorted by basis and maturity from historical data. In the maturity dimension, I split futures contracts into portfolios with maturities of 2-3 months, 4-5 months, 6-7 months, 8-9 months, 10-11 months, and 12 months, because many commodity futures like gold futures have maturities with more than a 2-month interval. In the basis dimension, I still split commodities into five portfolios by quantiles. I compute the average $L M H_{F C}$ within each 
maturity group. Figure 3 reports the average $L M H_{F C}$ over maturities. The model curve is computed by applying the same method to the simulated data. The model curve matches the data reasonably well.

In the model, the persistence of the basis spread is determined jointly by the persistence of producers' real investment and investment shocks. Because the investment is the risk exposure to investment shocks, highly persistent investment helps to generate a persistent basis spread over maturity. Meanwhile, highly persistent investment shocks impact the futures price more than low persistent ones. But the spot price has zero exposure to investment shocks, because the current supply of commodities or the installed capital is not exposed to the shock. Therefore, the model-predicted term structure of the basis spread is hump-shaped.

\subsection{Irreversibility, capital adjustment cost, and the basis spread}

In order to examine the importance of producers' real investment frictions in generating the basis spread, I analysis the sensitivity of the basis spread to the irreversibility constraint and the slope parameter of capital adjustment costs $(\theta)$. Table 13 compares the average excess returns and volatilities of portfolios sorted by basis in the simulated data from different models.

First, I shut down the investment irreversibility constraint. In this case, commodity producers face symmetric capital adjustment costs with monthly $\theta=12$. As reported in Table 13 , the L-H portfolio still has a $3.61 \%$ average return. Low-basis commodities offer high futures returns, the same as in the benchmark case. In particular, the low-basis portfolio has a similar excess return of about $11 \%$ per year. But the excess return of the high-basis portfolio raises to $7.34 \%$ from $1.81 \%$ in the benchmark model. This is because the high-basis portfolio includes those commodities with producers who want to disinvest but are no longer restricted by the irreversible constraints.

Second, I solve the model with different monthly slope parameters of capital adjustment $\operatorname{costs}(\theta=6$ and $\theta=24)$, but keeping the irreversibility constraint. When I reduce $\theta$ to 6 , the average excess return of the L-H portfolio increases to $11.85 \%$ from $9.02 \%$ in the benchmark model. This is because commodity producers optimally choose higher investment facing lower adjustment costs when there is a positive demand shock. Since the investment of producers measures the risk exposure $(\beta)$ of commodity futures, there is a large difference in the risk exposure $(\beta)$ between low- and high-basis commodities in this case. Because of the same reason, when I raise monthly $\theta$ to 24 , the simulated average return of the $\mathrm{L}-\mathrm{H}$ portfolio reduces to $6.17 \%$.

To summarize, all these frictions are not crucial in generating the predictability of the 
commodity futures return from basis. They only affect the magnitude of the basis spread. This is because, in my two-factor model, the basis spread is generated through the correlation between investment shocks and the futures prices. Intuitively, real investment of producers is the risk exposure $(\beta)$. All these frictions only affect the absolute value of the risk exposure $(\beta)$, but not its sign.

\section{Conclusion}

In this paper, I investigate the futures returns in the cross section of commodities. In the empirical part, I sort commodities into portfolios by basis and introduce a two-factor model to summarize the cross-sectional average returns of these portfolios. The two-factor model passes many empirical tests. Furthermore, I find that the cross-sectional return difference (the basis spread) is negatively correlated with investment shocks. With the negative risk price of investment shocks documented in Papanikolaou (2010), this finding suggests that the basis spread can be a risk premium of investment shocks.

In my theory part, I construct a dynamic equilibrium model extending KLY to replicate this negative correlation as well as the positive basis spread under the assumption of the negative risk price of investment shocks. The model also replicates the average returns of the five portfolios and many major empirical tests. This paper provides a potential macro risk explanation of the basis spread in contrast to the classic hedging pressure theory of the commodity futures premium (Keynes (1923) and others).

The rationality of other cross-sectional return spreads in commodity futures such as the momentum effect (GHR) and the "value premium" (Asness, Moskowitz, and Pedersen (2009)) would also be interesting topics to investigate in the future. 


\section{References}

[1] V. V. Acharya, L. A. Lochstoer, and T. Ramadorai. Limits to arbitrage and hedging: Evidence from commodity markets. Working Paper, 2010.

[2] C. S. Asness, T. J. Moskowitz, and L. H. Pedersen. Value and momentum everywhere. Working Paper, 2009.

[3] R. Bansal and A. Yaron. Risks for the long run: A potential resolution of asset pricing puzzles. Journal of Finance, 59(4):1481-1509, 2004.

[4] S. Bazdresch, F. Belo, and X. Lin. Labor hiring, investment and stock return predictability in the cross section. Working Paper, 2009.

[5] H. Bessembinder. Systematic risk, hedging pressure, and risk premiums in futures markets. Review of Financial Studies, 5(4):637-667, 1992.

[6] R. J. Caballero and R. S. Pindyck. Uncertainty, investment, and industry evolution. International Economic Review, 37:641-662, 1996.

[7] M. M. Carhart. On persistence in mutual fund performance. Journal of Finance, 52(1):5782, 1997.

[8] M. Carlson, A. Fisher, and R. Giammarino. Corporate investment and asset price dynamics: Implications for the cross-section of returns. Journal of Finance, 59(6):2577-2603, 2004 .

[9] M. Carlson, Z. Khokher, and S. Titman. Equilibrium exhaustible resource price dynamics. Journal of Finance, 62(4):1663-1703, 2007.

[10] J. Casassus and P. Collin-Dufresne. Stochastic convenience yield implied from commodity futures and interest rates. Journal of Finance, 60(5):2283-2331, 2005.

[11] J. Casassus, P. Collin-Dufresne, and B. R. Routledge. Equilibrium commodity prices with irreversible investment and non-linear technologies. Working Paper, 2009.

[12] J. H. Cochrane. Production-based asset pricing and the link between stock returns and economic fluctuations. Journal of Finance, 46(1):209-237, 1991.

[13] J. H. Cochrane. Asset pricing. 2005. 
[14] J. H. Cochrane and M. Piazzesi. Bond risk premia. American Economic Review, 95(1):138$160,2005$.

[15] R. W. Cooper and J. C. Haltiwanger. On the nature of capital adjustment costs. Working Paper, 2000.

[16] F. A. de Roon, T. E. Nijman, and C. Veld. Hedging pressure effects in futures markets. Journal of Finance, 55(3):1437-1456, 2000.

[17] A. Deaton and G. Laroque. On the behaviour of commodity prices. Review of Economic Studies, 59(1):1-23, 1992.

[18] A. Deaton and G. Laroque. Competitive storage and commodity price dynamics. Journal of Political Economy, 104(5):896-923, 1996.

[19] A. Eisfeldt and D. Papanikolaou. Organization capital and the cross-section of expected returns. Working Paper, 2010.

[20] C. B. Erb and C. R. Harvey. The strategic and tactical value of commodity futures. Financial Analysts Journal, 62(2):69-97, 2006.

[21] E. Etula. Broker-dealer risk appetite and commodity returns. Working Paper, 2009.

[22] E. Fama and K. R. French. The cross-section of expected stock returns. Journal of Finance, 47(2):427-465, 1992.

[23] E. Fama and K. R. French. Common risk factors in the returns on stocks and bonds. Journal of Financial Economics, 33(1):3-56, 1993.

[24] E. F. Fama and K. R. French. Commodity futures prices: Some evidence on forecast power, premiums, and the theory of storage. Journal of Business, 60(1):55-73, 1987.

[25] E. F. Fama and J. D. MacBeth. Risk, return, and equilibrium: empirical tests. Journal of Political Economy, 47(3):607, 1973.

[26] J. D. M. Fisher. The dynamic effects of neutral and investment-specific technology shocks. Journal of Political Economy, 114(3):413-451, 2006.

[27] J. Gomes, L. Kogan, and L. Zhang. Equilibrium cross section of returns. Journal of Political Economy, 111(4):693-732, 2003. 
[28] J. F. Gomes, L. Kogan, and M. Yogo. Durability of output and expected stock returns. Journal of Political Economy, 117(5):941-986, 2009.

[29] G. B. Gorton, F. Hayashi, and K. G. Rouwenhorst. The fundamentals of commodity futures returns. Working Paper, 2008.

[30] G. B. Gorton and K. G. Rouwenhorst. Facts and fantasies about commodity futures. Working Paper, 2005.

[31] J. Greenwood, Z. Hercowitz, and P. Krusell. Long-run implications of investment-specific technological change. American Economic Review, 87(3):342-362, 1997.

[32] J. Greenwood, Z. Hercowitz, and P. Krusell. The role of investment-specific technological change in the business cycle. European Economic Review, 44(1):91-115, 2000.

[33] L. P. Hansen. Large sample properties of generalized method of moments estimators. Econometrica, 50(4):1029-1054, 1982.

[34] D. Hirshleifer. Residual risk, trading costs, and commodity futures risk premia. Review of Financial Studies, 1(2):173-193, 1988.

[35] D. Hirshleifer. Hedging pressure and futures price movements in a general equilibrium model. Econometrica, 58(2):411-428, 1990.

[36] H. G. Hong and M. Yogo. Digging into commodities. Working paper, 2009.

[37] H. G. Hong and M. Yogo. Commodity market interest and asset return predictability. Working paper, 2010.

[38] R. D. Israelsen. Investment based valuation. Working paper, 2010.

[39] A. Justiniano, G. E. Primiceri, and A. Tambalotti. Investment shocks and business cycles. Journal of Monetary Economics, 57(2):132-145, 2010.

[40] J. M. Keynes. Some aspects of commodity markets. Manchester Guardian Commercial, 13:784-786, 1923.

[41] L. Kogan, D. Livdan, and A. Yaron. Oil futures prices in a production economy with investment constraints. Journal of Finance, 64(3):1345-1375, 2009.

[42] L. Kogan and D. Papanikolaou. Growth opportunities, technology shocks and asset prices. Working Paper, 2010. 
[43] L. Kogan and D. Papanikolaou. Investment shocks, firm characteristics and the crosssection of expected returns. Working Paper, 2010.

[44] L.-A. Kuehn and L. Schmid. Investment-based corporate bond pricing. Working Paper, 2010.

[45] M. Lettau and J. A. Wachter. Why is long-horizon equity less risky? a duration-based explanation of the value premium. Journal of Finance, 62(1):55-92, 2007.

[46] X. Lin. Endogenous technological progress and the cross section of stock returns. Working Paper, 2010.

[47] R. H. Litzenberger and N. Rabinowitz. Backwardation in oil futures markets: Theory and empirical evidence. Journal of Finance, 50(5):1517-1545, 1995.

[48] L. X. Liu, T. M. Whited, and L. Zhang. Investment-based expected stock returns. Journal of Political Economy, 117(6):1105-1139, 2009.

[49] R. E. Lucas and E. C. Prescott. Investment under uncertainty. Econometrica, 39(5):659681, 1971.

[50] H. Lustig, N. Roussanov, and A. Verdelhan. Common risk factors in currency markets. Working Paper, 2010.

[51] H. Lustig and A. Verdelhan. The cross section of foreign currency risk premia and consumption growth risk. American Economic Review, 97(1):89-17, 2007.

[52] D. Papanikolaou. Investment shocks and asset prices. Working Paper, 2010.

[53] B. R. Routledge, D. J. Seppi, and C. S. Spatt. Equilibrium forward curves for commodities. Journal of Finance, 55(3):1297-1338, 2000.

[54] K. G. Rouwenhorst. Asset pricing implications of equilibrium business cycle models. In Frontiers of Business Cycle Research, pages 293-330, 1995.

[55] E. S. Schwartz. The stochastic behavior of commodity prices: Implications for valuation and hedging. Journal of Finance, 52(3):923-973, 1997.

[56] E. S. Schwartz and J. E. Smith. Short-term variations and long-term dynamics in commodity prices. Management Science, 46(7):893-911, 2000. 
[57] K. Tang and W. Xiong. Index investment and financialization of commodities. Working Paper, 2010.

[58] G. Tauchen. Finite state markov-chain approximations to univariate and vector autoregressions. Economics Letters, 20(2):177-181, 1986.

[59] A. B. Trolle and E. S. Schwartz. Unspanned stochastic volatility and the pricing of commodity derivatives. Review of Financial Studies, 22(11):4423-4461, 2009.

[60] L. Zhang. The value premium. Journal of Finance, 60(1):67-103, 2005. 


\section{Appendices}

\subsection{Tests of standard factor models}

In this section, I document the failure of standard factor models in the stock market in explaining the basis spread. Using the five commodity futures portfolios sorted by basis as test assets, I test the standard CAPM, the Fama-French three-factor model (Fama and French (1992)), and the Carhart four-factor model (Carhart (1997)). The time-series regressions results are reported in Tables 14, 15, and 16 correspondingly. Commodity futures portfolio returns have little correlation with these risk factors. The abnormal returns (alpha) of these portfolios are significantly positive. Therefore, the risk exposure to these common risk factors in the stock market cannot explain the basis spread.

\subsection{Detrended social planner's problem}

I solve the social planner's problem using the value function iteration. This numerical method only applies to stationary models. Therefore, I detrend my model variables. The Bellman equation of the social planner is

$$
\begin{aligned}
S V_{t}= & \max _{I_{t}}\left\{\frac{1}{1-\eta} X_{t}^{\eta} Z_{t}^{\eta} K_{t}^{1-\eta}-I_{t}-\frac{\theta}{2}\left(\frac{I_{t}}{K_{t}}\right)^{2} K_{t}+\mathrm{E}_{t}\left[M_{t+1} S V_{t+1}\right]\right\} \\
& \text { s.t. } I_{t} \geq 0 .
\end{aligned}
$$

Because both aggregate and idiosyncratic demand shocks follow random walk processes, I detrend all variables by letting $S V_{t}=\frac{S V_{t}}{X_{t} Z_{t}}, \hat{K}_{t}=\frac{K_{t}}{X_{t} Z_{t}}$, and $\hat{I}_{t}=\frac{I_{t}}{X_{t} Z_{t}}$. The detrended value function of the social planer reduces to a function of two state variables, both investment shocks $\left(Y_{t}\right)$ and detrended capital $\left(\hat{K}_{t}\right)$, as

$$
\begin{aligned}
\hat{S V}\left(Y_{t}, \hat{K}_{t}\right)= & \max _{\hat{I}_{t}}\left\{\frac{1}{1-\eta} \hat{K}_{t}^{1-\eta}-\hat{I}_{t}-\frac{\theta}{2}\left(\frac{\hat{I}_{t}}{\hat{K}_{t}}\right)^{2} \hat{K}_{t}\right. \\
& \left.+\mathrm{E}_{t}\left[M_{t+1} e^{\mu_{x}+\sigma_{x} e_{t+1}+\sigma_{z} \epsilon_{t+1}} \hat{S V}\left(Y_{t+1}, \hat{K}_{t+1}\right)\right]\right\} \\
& \text { s.t. } \hat{I}_{t} \geq 0 .
\end{aligned}
$$

The law of motion for the detrended capital is

$$
\hat{K}_{t+1}=e^{-\mu_{x}-\sigma_{x} e_{t+1}-\sigma_{z} \epsilon_{t+1}}\left[(1-\delta) \hat{K}_{t}+Y_{t} \hat{I}_{t}\right] .
$$

From the inverse demand function, we can derive the spot price dynamics as

$$
P_{t}=\hat{K}_{t}^{-\eta}
$$


which is mean-reverting given that the detrended capital is stationary. This is consistent with the empirical fact that commodity spot prices are mean-reverting. The state variables of the detrend economy are $\left(Y_{t}, \hat{K}_{t}\right)$. After detrending, both aggregate and idiosyncratic demand shocks reduce to independent and identically distributed (i.i.d.) Gaussian shocks $\left(e_{t}, \epsilon_{t}\right)$.

\subsection{Numerical procedure details}

The numerical solution of my model involves two steps: value function iteration and Monte Carlo simulation. The value function iteration solves for the optimal investment policy of producers $\left(\hat{I}_{t+1}\left(y_{t}, \hat{K}_{t}\right)\right)$. Because this paper is focused on product price implications, in contrast to papers on stock prices, the value function itself is less important. Given the investment policy function, we can solve for the spot price using the detrended inverse demand function (Equation 38). I compute the futures prices over maturities by taking the expectation in Equation 26 recursively. By simulating the futures price, capital, and exogenous shocks jointly, I create 1,000 panels of 35 commodities with futures prices with maturities up to 12 months. The model implications are performed on these panels of simulated data.

The first step of the value function iteration is to discretize the state space of exogenous shocks. My model has three shocks. The log investment shock $y_{t}$ is assumed to follow an $\operatorname{AR}(1)$ process. I follow previous literature (e.g., Zhang (2005)) in using the Rouwenhorst (1995) method to discretize this shock. Compared to Tauchen (1986), this method does a better job in discretizing highly persistent ( $\rho$ close to 1 ) shocks. The i.i.d. innovations $e_{t}$ in the aggregate demand shock and $\epsilon_{t}$ in the idiosyncratic demand shock are discretized using the same method by setting $\rho=0$. I use eleven grid points for $y_{t}$ and eleven grid points for both $e_{t}$ and $\epsilon_{t}$.

The detrended capital $\hat{K}$ is discretized to be evenly spaced in its log space as $\log \hat{K}_{j}=$ $\log \hat{K}_{j-1}+\left(\log \hat{K}_{\max }-\log \hat{K}_{\text {min }}\right) /(N-1)$. The upper bound $\log \hat{K}_{\max }$ and the lower bound $\log \hat{K}_{\text {min }}$ of detrended capital are chosen so that simulated detrended capitals are always between the boundaries. I choose $N_{K}=100$ for the coarse capital grid. For every value function iteration, a finer grid of capital is used to search for more precise optimal capital next period $\left(\hat{K}_{t+1}\right)$ after the search on the coarse grid. I choose $N_{K}=50$ for the finer grid near the optimal next period capital $\left(\hat{K}_{t+1}\right)$ on the coarse grid.

Monte Carlo simulations are performed on the grids of demand shocks $\left(e_{t}, \epsilon_{t}\right)$ but off-grid for $\log$ investment shocks $\left(y_{t}\right)$ and detrended capital $\left(\hat{K}_{t}\right)$. Interpolation is widely applied in both the value function iteration and simulation. 


\begin{tabular}{|c|c|c|c|c|c|c|c|c|}
\hline Sector & Commodity & Symbol & $\mathrm{N}$ & Basis & $\begin{array}{r}\text { Freq. of } \\
\text { bw. }\end{array}$ & $\overline{\mathrm{E}\left[R^{e}\right]}$ & $\overline{\overline{\sigma \sigma}\left[R^{e}\right]}$ & $\begin{array}{r}\text { Sharpe } \\
\text { ratio }\end{array}$ \\
\hline \multirow[t]{17}{*}{ Agriculture } & Barley & WA & 235 & 3.66 & 28.51 & -0.24 & 19.62 & -1.21 \\
\hline & Butter & 02 & 141 & 3.68 & 34.04 & 3.66 & 27.22 & 13.46 \\
\hline & Canola & WC & 377 & 2.98 & 33.16 & -0.18 & 19.82 & -0.89 \\
\hline & Cocoa & $\mathrm{CC}$ & 452 & 2.61 & 25.88 & 4.52 & 30.32 & 14.90 \\
\hline & Coffee & $\mathrm{KC}$ & 420 & 2.57 & 37.38 & 6.00 & 36.52 & 16.44 \\
\hline & Corn & C- & 468 & 6.03 & 23.29 & -0.01 & 23.35 & -0.04 \\
\hline & Cotton & $\mathrm{CT}$ & 452 & 1.75 & 36.50 & 3.60 & 22.96 & 15.69 \\
\hline & Flaxseed & WF & 295 & 1.55 & 29.15 & -1.53 & 18.02 & -8.50 \\
\hline & Lumber & $\mathrm{LB}$ & 468 & 5.63 & 33.55 & -1.13 & 22.80 & -4.98 \\
\hline & Oats & O- & 468 & 5.65 & 31.20 & 0.44 & 28.90 & 1.53 \\
\hline & Orange juice & $\mathrm{JO}$ & 448 & 3.08 & 36.83 & 2.32 & 29.56 & 7.86 \\
\hline & Rough rice & $\mathrm{RR}$ & 265 & 7.56 & 26.42 & -1.50 & 25.01 & -6.01 \\
\hline & Soybean meal & SM & 468 & -0.20 & 44.87 & 7.80 & 28.63 & 27.25 \\
\hline & Soybean oil & $\mathrm{BO}$ & 468 & -0.79 & 38.89 & 8.44 & 29.44 & 28.68 \\
\hline & Soybeans & S- & 468 & 0.58 & 37.39 & 5.99 & 26.25 & 22.81 \\
\hline & Sugar & SB & 452 & 2.47 & 43.14 & 7.50 & 39.13 & 19.18 \\
\hline & Wheat & W- & 468 & 2.88 & 38.89 & 2.79 & 23.76 & 11.72 \\
\hline \multirow{5}{*}{ Energy } & Crude oil & CL & 295 & -4.25 & 67.12 & 10.56 & 27.87 & 37.89 \\
\hline & Gasoline & $\mathrm{RB}$ & 275 & -8.09 & 70.91 & 12.82 & 30.18 & 42.47 \\
\hline & Heating oil & $\mathrm{HO}$ & 345 & -1.49 & 55.94 & 9.50 & 28.65 & 33.15 \\
\hline & Natural gas & NG & 216 & 3.63 & 43.98 & 8.66 & 34.63 & 25.00 \\
\hline & Propane & $\mathrm{PN}$ & 247 & -5.53 & 57.89 & 14.28 & 34.18 & 41.77 \\
\hline \multirow[t]{6}{*}{ Livestock } & Broilers & $\mathrm{BR}$ & 19 & -4.58 & 68.42 & 1.49 & 7.28 & 20.53 \\
\hline & Feeder cattle & $\mathrm{FC}$ & 443 & -0.35 & 53.50 & 4.43 & 14.28 & 31.01 \\
\hline & Lean hogs & $\mathrm{LH}$ & 468 & -2.66 & 59.40 & 7.98 & 22.34 & 35.70 \\
\hline & Live cattle & $\mathrm{LC}$ & 468 & -0.46 & 50.64 & 4.55 & 14.92 & 30.46 \\
\hline & Live hogs & LG & 321 & -3.80 & 60.12 & 9.83 & 23.60 & 41.67 \\
\hline & Pork bellies & $\mathrm{PB}$ & 468 & 0.75 & 50.85 & 2.72 & 32.66 & 8.32 \\
\hline \multirow[t]{6}{*}{ Metals } & Aluminum & $\mathrm{AL}$ & 215 & -1.06 & 55.35 & 5.46 & 19.11 & 28.56 \\
\hline & Copper & HG & 460 & -0.69 & 41.52 & 5.66 & 25.28 & 22.37 \\
\hline & Gold & $\mathrm{GC}$ & 400 & 6.24 & 0.00 & 0.43 & 19.88 & 2.18 \\
\hline & Palladium & PA & 362 & 2.16 & 32.32 & 10.21 & 35.19 & 29.01 \\
\hline & Platinum & PL & 450 & 3.36 & 22.89 & 3.85 & 28.17 & 13.66 \\
\hline & Silver & SI & 460 & 6.67 & 1.09 & 0.93 & 31.61 & 2.95 \\
\hline
\end{tabular}

Table 1: Summary statistics of commodity futures for every individual commodity in the sample. The sample includes monthly close quotes of futures of maturities up to 12 months of 34 commodities from January 1970 to December 2008. $N$ is the number of monthly observations available for a commodity. The basis column reports the historical average basis of a commodity. The "freq. of bw." column reports the frequency of a commodity futures curve that is in backwardation. A commodity is in backwardation if its basis is negative. $E\left(R^{e}\right)$ and $\sigma\left(R^{e}\right)$ are the annualized historical average and standard deviation of futures excess returns of individual commodities. 


\begin{tabular}{|c|c|c|c|c|c|c|}
\hline & Low & 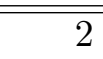 & $\overline{3}$ & 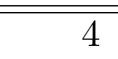 & High & L-H \\
\hline \multicolumn{7}{|c|}{ Panel A: Full sample } \\
\hline & \multicolumn{6}{|c|}{ Futures excess return } \\
\hline Mean & 11.05 & 8.72 & 4.82 & 2.69 & 0.79 & 10.26 \\
\hline Std & 19.56 & 15.90 & 16.69 & 15.94 & 17.66 & 20.53 \\
\hline \multirow[t]{2}{*}{ Sharpe ratio } & 56.50 & 54.85 & 28.90 & 16.85 & 4.45 & 50.00 \\
\hline & \multicolumn{6}{|c|}{ Spot change in percentage } \\
\hline Mean & -0.80 & 7.25 & 6.80 & 12.38 & 20.33 & -21.13 \\
\hline \multirow[t]{2}{*}{ Std } & 24.98 & 17.94 & 18.13 & 17.30 & 23.64 & 29.53 \\
\hline & \multicolumn{6}{|c|}{ Basis } \\
\hline Mean & -17.11 & -4.09 & 2.77 & 8.02 & 16.97 & \\
\hline Std & 32.25 & 19.66 & 15.39 & 12.74 & 19.29 & \\
\hline \multicolumn{7}{|c|}{ Panel B: Subsample 1985-2008 } \\
\hline & \multicolumn{6}{|c|}{ Futures excess return } \\
\hline Mean & 7.94 & 5.43 & 4.25 & 1.81 & 0.23 & 7.72 \\
\hline Std & 16.33 & 13.56 & 14.38 & 12.72 & 14.60 & 18.92 \\
\hline \multirow[t]{2}{*}{ Sharpe ratio } & 48.64 & 40.05 & 29.53 & 14.21 & 1.55 & 40.81 \\
\hline & \multicolumn{6}{|c|}{ Spot change in percentage } \\
\hline Mean & -2.23 & 4.63 & 7.30 & 8.89 & 19.32 & -21.55 \\
\hline \multirow[t]{2}{*}{ Std } & 23.23 & 16.55 & 16.99 & 13.93 & 21.36 & 29.06 \\
\hline & \multicolumn{6}{|c|}{ Basis } \\
\hline Mean & -16.72 & -3.99 & 2.22 & 7.44 & 16.82 & \\
\hline Std & 26.05 & 15.32 & 11.12 & 10.35 & 18.01 & \\
\hline
\end{tabular}

Table 2: Key moments of the five commodity portfolios sorted by basis. Panel A reports the portfolio return moments of the full sample including monthly close quotes of futures of maturities up to 12 months of 34 commodities from January 1970 to December 2008. Panel $\mathrm{B}$ reports the portfolio return moments of a subsample of the same set of commodities from January 1985 to December 2008. Portfolios are rebalanced in the last trading day of every month. Futures excess return is defined as the fully collateralized return of longing a futures contract. Spot change is defined as the percentage change in spot prices. Basis is defined as the annualized log difference between futures prices with the longest maturity and the shortest maturity available. 


\begin{tabular}{crrrrr}
\hline \hline \multicolumn{7}{c}{ Panel A: Full sample } \\
\hline Portfolio & Low & 2 & 3 & 4 & High \\
\hline Low & 69.5 & 20.4 & 4.7 & 1.5 & 1.2 \\
2 & 21.7 & 51.2 & 20.6 & 5.2 & 2.6 \\
3 & 5.8 & 21.9 & 48.9 & 21.0 & 4.8 \\
4 & 1.9 & 4.5 & 21.1 & 53.5 & 19.8 \\
High & 1.2 & 2.0 & 4.6 & 18.8 & 71.5 \\
\hline
\end{tabular}

Panel B: Subsample 1985-2008

\begin{tabular}{crrrrr}
\hline Portfolio & Low & 2 & 3 & 4 & High \\
\hline Low & 68.9 & 20.3 & 5.4 & 1.9 & 1.2 \\
2 & 21.8 & 51.8 & 19.9 & 5.1 & 2.8 \\
3 & 5.6 & 21.3 & 50.6 & 20.5 & 4.0 \\
4 & 2.2 & 4.5 & 20.0 & 54.2 & 19.9 \\
High & 1.5 & 2.1 & 4.2 & 18.4 & 72.2 \\
\hline \hline
\end{tabular}

Table 3: Transition probability matrix of the five portfolios sorted by basis. Panel A reports the portfolio transition probability of the full sample including monthly close quotes of futures of maturities up to 12 months of 34 commodities from January 1970 to December 2008. Panel B reports the portfolio transition probability of a subsample of the same set of commodities from January 1985 to December 2008. Portfolios are rebalanced in the last trading day of every month. 


\begin{tabular}{|c|c|c|c|c|c|c|}
\hline & Low & $\overline{1}$ & $\overline{2}$ & 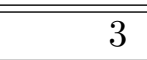 & "High & 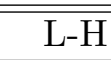 \\
\hline \multicolumn{7}{|c|}{ Panel A: Full sample } \\
\hline $\begin{array}{l}\text { Alpha } \\
(t \text {-stat })\end{array}$ & $\begin{array}{r}4.33 \\
(1.97)\end{array}$ & $\begin{array}{r}3.10 \\
(2.00)\end{array}$ & $\begin{array}{r}-1.40 \\
(-1.00)\end{array}$ & $\begin{array}{r}-2.64 \\
(-1.76)\end{array}$ & $\begin{array}{r}-4.82 \\
(-2.63)\end{array}$ & $\begin{array}{r}9.16 \\
(2.68)\end{array}$ \\
\hline $\begin{array}{l}M k t \\
(t \text {-stat) }\end{array}$ & $\begin{array}{r}1.12 \\
(17.67)\end{array}$ & $\begin{array}{r}0.93 \\
(19.55)\end{array}$ & $\begin{array}{r}1.04 \\
(24.86)\end{array}$ & $\begin{array}{r}0.89 \\
(22.05)\end{array}$ & $\begin{array}{r}0.93 \\
(12.70)\end{array}$ & $\begin{array}{r}0.18 \\
(1.58)\end{array}$ \\
\hline$R^{2}(\%)$ & 59.35 & 62.83 & 70.06 & 56.16 & 50.83 & 1.46 \\
\hline \multicolumn{7}{|c|}{ Panel B: Subsample 1985-2008 } \\
\hline $\begin{array}{l}\text { Alpha } \\
(t \text {-stat })\end{array}$ & $\begin{array}{r}3.18 \\
(1.49)\end{array}$ & $\begin{array}{r}1.28 \\
(0.75)\end{array}$ & $\begin{array}{r}-0.49 \\
(-0.33)\end{array}$ & $\begin{array}{r}-1.72 \\
(-1.07)\end{array}$ & $\begin{array}{r}-3.37 \\
(-1.57)\end{array}$ & $\begin{array}{r}6.54 \\
(1.74)\end{array}$ \\
\hline $\begin{array}{l}M k t \\
(t \text {-stat) }\end{array}$ & $\begin{array}{r}1.11 \\
(13.99)\end{array}$ & $\begin{array}{r}0.97 \\
(15.15)\end{array}$ & $\begin{array}{r}1.11 \\
(18.56)\end{array}$ & $\begin{array}{r}0.82 \\
(17.61)\end{array}$ & $\begin{array}{r}0.84 \\
(9.46)\end{array}$ & $\begin{array}{r}0.27 \\
(1.95)\end{array}$ \\
\hline$R^{2}(\%)$ & 54.85 & 60.41 & 69.83 & 49.49 & 38.99 & 2.48 \\
\hline
\end{tabular}

Table 4: Test-series tests of commodity CAPM. The commodity market factor is constructed as the equally weighted commodity futures across commodities and maturities in the sample. Panel A reports the portfolio alphas and market betas of the full sample including monthly close quotes of futures of maturities up to 12 months of 34 commodities from January 1970 to December 2008. Panel B reports the portfolio alphas and market betas of a subsample of the same set of commodities from January 1985 to December 2008. Portfolios are rebalanced in the last trading day of every month. 


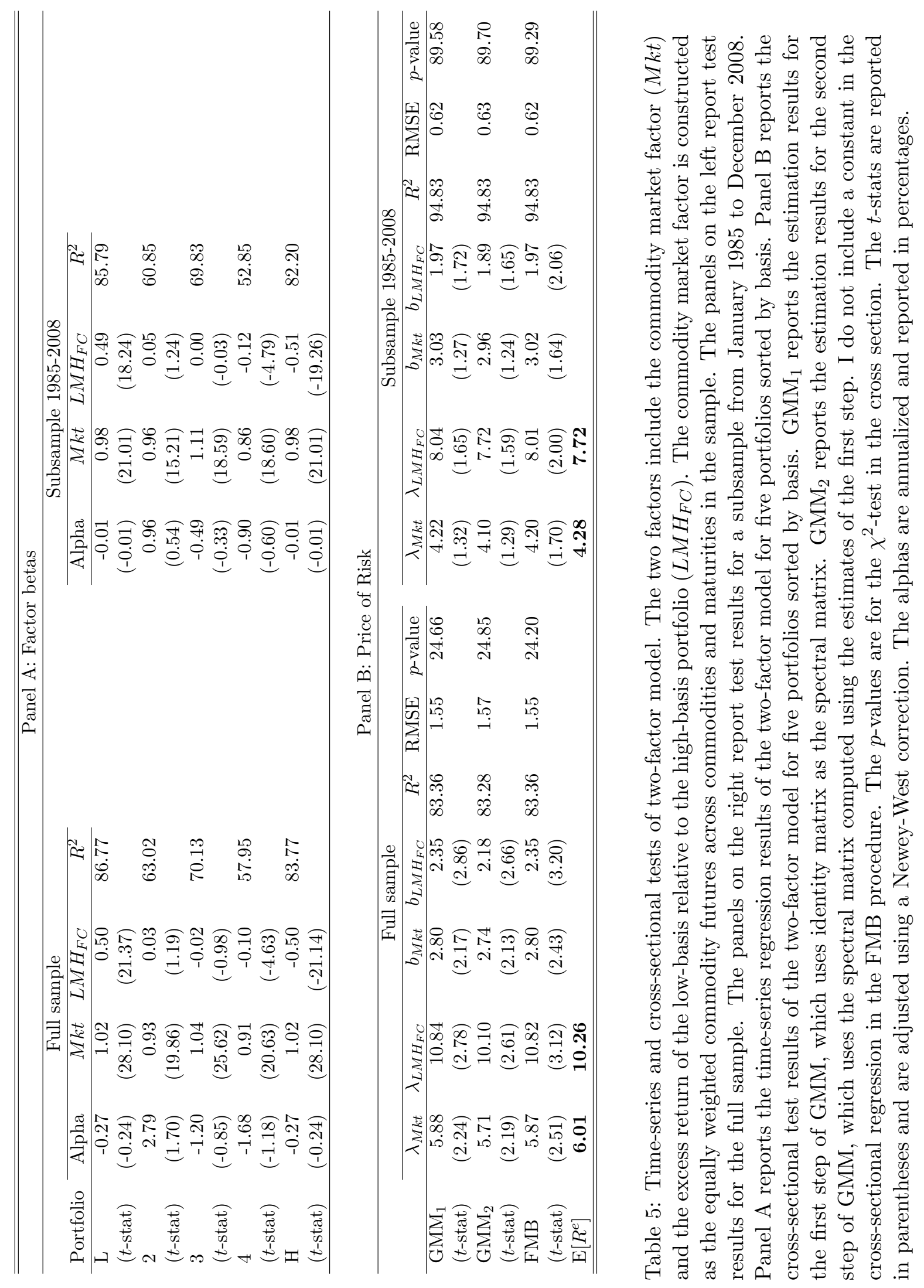




\begin{tabular}{crrrrr}
\hline \hline \multicolumn{7}{c}{ Panel A: Full sample } \\
\hline Portfolio & 1 & 2 & 3 & 4 & 5 \\
\hline L & 0.52 & 0.71 & -0.45 & -0.16 & 0.00 \\
2 & 0.42 & 0.11 & 0.50 & 0.39 & -0.64 \\
3 & 0.47 & -0.04 & 0.40 & 0.24 & 0.75 \\
4 & 0.39 & -0.33 & 0.22 & -0.82 & -0.12 \\
H & 0.43 & -0.62 & -0.58 & 0.31 & -0.09 \\
\% Var. & 0.60 & 0.15 & 0.11 & 0.08 & 0.06 \\
\hline
\end{tabular}

Panel B: Subsample 1985-2008

\begin{tabular}{crrrrr}
\hline & \multicolumn{5}{c}{ PC - Excess returns } \\
Portfolio & 1 & 2 & 3 & 4 & 5 \\
\hline L & 0.52 & 0.61 & -0.57 & -0.16 & -0.06 \\
2 & 0.44 & 0.13 & 0.53 & 0.30 & -0.65 \\
3 & 0.51 & 0.01 & 0.32 & 0.29 & 0.74 \\
4 & 0.36 & -0.32 & 0.24 & -0.84 & -0.01 \\
H & 0.38 & -0.71 & -0.49 & 0.29 & -0.15 \\
\% Var. & 0.55 & 0.18 & 0.12 & 0.08 & 0.07 \\
\hline \hline
\end{tabular}

Table 6: Principal component analysis of the excess returns of the five portfolios sorted by basis. For each panel, the first five rows report the principal component coefficients of portfolios. The last row reports the percentage of the total variance (\% Var.) captured by each principal component. Panel A reports the results of the full sample including monthly close quotes of futures of maturities up to 12 months of 34 commodities from January 1970 to December 2008. Panel B reports the results of a subsample of the same set of commodities from January 1985 to December 2008. Portfolios are rebalanced in the last trading day of every month. 


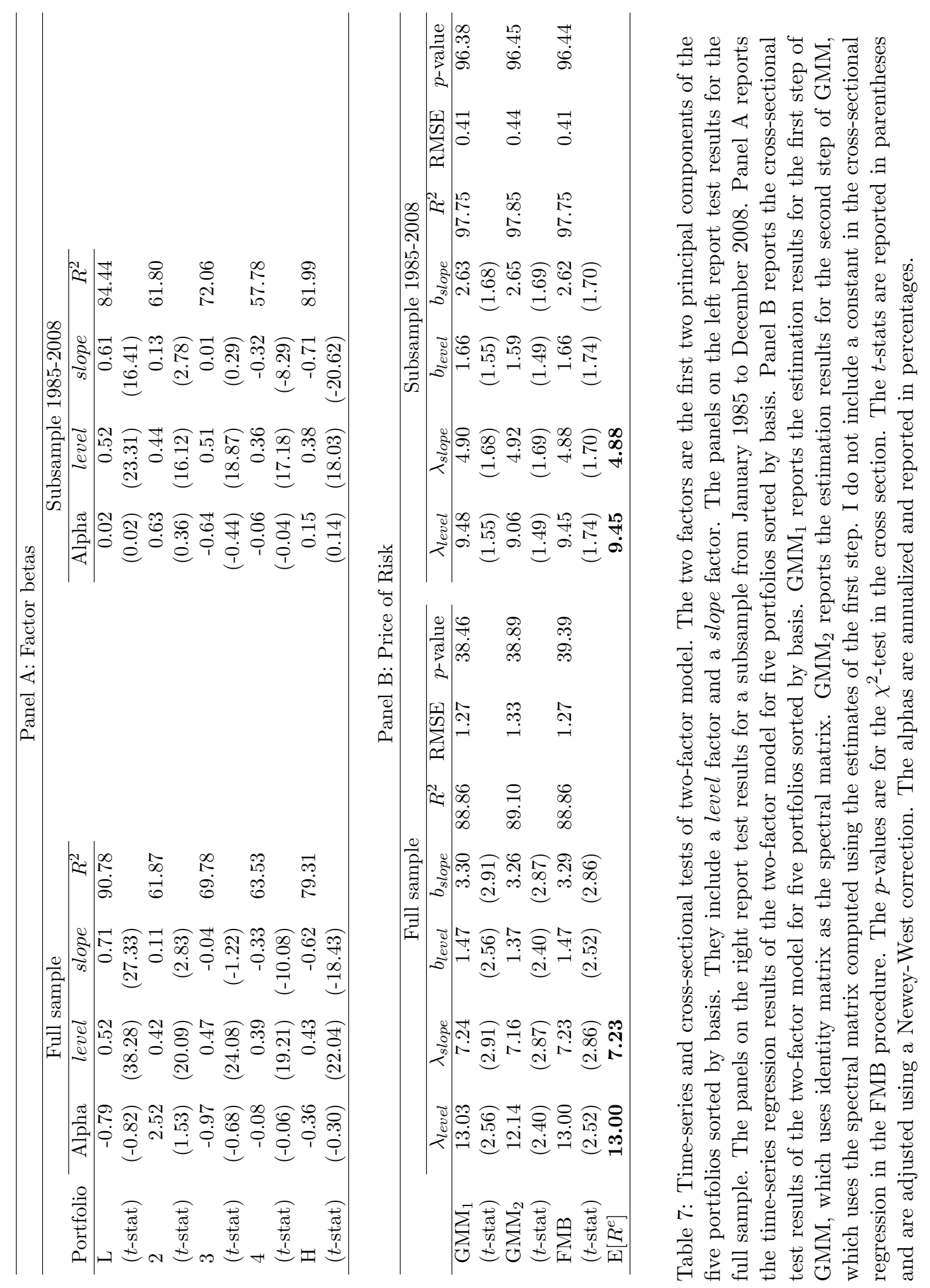




\begin{tabular}{|c|c|c|c|c|c|c|}
\hline & Low & 2 & 3 & 4 & "High & H-L \\
\hline \multicolumn{7}{|c|}{ Panel A: Full sample } \\
\hline & \multicolumn{6}{|c|}{ Basis } \\
\hline Mean & 5.56 & 3.74 & 1.41 & 0.47 & -4.78 & \\
\hline Std & 29.07 & 25.16 & 22.76 & 25.01 & 37.82 & \\
\hline
\end{tabular}

Futures excess return

$\begin{array}{lrrrrrr}\text { Mean } & 2.69 & 5.03 & 6.18 & 5.37 & 9.26 & 6.57 \\ \text { Std } & 19.38 & 16.69 & 16.38 & 16.57 & 20.48 & 23.65 \\ \text { Sharpe ratio (\%) } & 13.88 & 30.16 & 37.73 & 32.37 & 45.23 & 27.79\end{array}$

\begin{tabular}{lrrrrrr} 
& \multicolumn{7}{c}{ Pre-formation $\beta$} \\
Mean & -0.70 & -0.26 & -0.03 & 0.19 & 0.61 & 1.31 \\
Std & 0.26 & 0.14 & 0.10 & 0.12 & 0.27 & 0.45
\end{tabular}

\begin{tabular}{lllllll} 
& \multicolumn{7}{c}{ Post-formation $\beta$} \\
Mean & -0.17 & -0.11 & -0.08 & 0.02 & 0.19 & 0.36 \\
$($-stat $)$ & -3.09 & -3.11 & -2.31 & 0.54 & 4.08 & 4.29 \\
\hline
\end{tabular}

Panel B: Subsample 1985-2008

\begin{tabular}{|c|c|c|c|c|c|c|}
\hline \multirow[b]{2}{*}{ Mean } & \multicolumn{6}{|c|}{ Basis } \\
\hline & 4.88 & 3.47 & 1.01 & -0.20 & -3.72 & \\
\hline \multirow[t]{2}{*}{ Std } & 27.78 & 24.80 & 21.04 & 20.81 & 32.13 & \\
\hline & \multicolumn{6}{|c|}{ Futures excess return } \\
\hline Mean & 1.77 & 1.46 & 3.78 & 2.94 & 6.84 & 5.06 \\
\hline Std & 16.41 & 14.12 & 12.07 & 12.58 & 18.86 & 21.41 \\
\hline \multirow[t]{2}{*}{ Sharpe ratio (\%) } & 10.80 & 10.37 & 31.28 & 23.36 & 36.24 & 23.65 \\
\hline & \multicolumn{6}{|c|}{ Pre-formation $\beta$} \\
\hline Mean & -0.73 & -0.29 & -0.05 & 0.18 & 0.64 & 1.36 \\
\hline \multirow[t]{2}{*}{ Std } & 0.25 & 0.16 & 0.12 & 0.14 & 0.31 & 0.50 \\
\hline & \multicolumn{6}{|c|}{ Post-formation $\beta$} \\
\hline Mean & -0.26 & -0.11 & -0.12 & 0.04 & 0.19 & 0.44 \\
\hline$(t$-stat) & -3.75 & -2.84 & -3.16 & 0.98 & 2.93 & 3.93 \\
\hline
\end{tabular}

Table 8: Key moments of the five commodity portfolios sorted by the risk exposure (preformation $\beta$ ) to the $L M H_{F C}$ factor. Pre-formation $\beta$ is defined as the coefficient of regressing commodity futures returns to the LMH factor on a 12-month moving window that ends in the month before formation. Panel A reports the statistics of the full sample including monthly close quotes of futures of maturities up to 12 months of 34 commodities from January 1970 to December 2008. Panel B reports the statistics of a subsample of the same set of commodities from January 1985 to December 2008. Portfolios are rebalanced in the last trading day of every month. Post-formation $\beta$ is computed by regressing the portfolio excess return on the $L M H_{F C}$ factor. The $t$-stats are reported in parentheses and are adjusted using a Newey-West correction. 


\begin{tabular}{|c|c|c|c|c|c|c|}
\hline & Low & 2 & 3 & 4 & High & $\overline{\mathrm{L}-\mathrm{H}}$ \\
\hline \multicolumn{7}{|c|}{ Panel A: Full sample } \\
\hline $\begin{array}{l}\operatorname{Cov}\left(R_{j}^{e}, R_{M k t}^{e}\right) / \sigma_{M k t}^{2} \\
(t \text {-stat) }\end{array}$ & $\begin{array}{r}1.07 \\
(7.09)\end{array}$ & $\begin{array}{r}1.03 \\
(7.21)\end{array}$ & $\begin{array}{r}0.92 \\
(8.68)\end{array}$ & $\begin{array}{r}1.00 \\
(10.24)\end{array}$ & $\begin{array}{r}0.88 \\
(6.70)\end{array}$ & $\begin{array}{r}0.20 \\
(0.74)\end{array}$ \\
\hline $\begin{array}{l}\operatorname{Cov}\left(R_{j}^{e}, R_{I M C}^{e}\right) / \sigma_{I M C}^{2} \\
(t \text {-stat) }\end{array}$ & $\begin{array}{r}-0.05 \\
(-0.20)\end{array}$ & $\begin{array}{r}-0.01 \\
(-0.04)\end{array}$ & $\begin{array}{r}0.29 \\
(1.23)\end{array}$ & $\begin{array}{r}0.31 \\
(1.36)\end{array}$ & $\begin{array}{r}0.47 \\
(2.33)\end{array}$ & $\begin{array}{r}-0.52 \\
(-3.63)\end{array}$ \\
\hline $\begin{array}{l}\operatorname{Cov}\left(R_{j}^{e}, z^{\xi}\right) / \sigma_{z}^{2} \\
(t \text {-stat })\end{array}$ & $\begin{array}{r}3.44 \\
(1.64)\end{array}$ & $\begin{array}{r}-0.16 \\
(-0.15)\end{array}$ & $\begin{array}{r}0.23 \\
(0.34)\end{array}$ & $\begin{array}{r}1.98 \\
(1.72)\end{array}$ & $\begin{array}{r}2.25 \\
(1.85)\end{array}$ & $\begin{array}{r}1.19 \\
(0.45)\end{array}$ \\
\hline \multicolumn{7}{|c|}{ Panel B: Subsample 1985-2008 } \\
\hline $\begin{array}{l}\operatorname{Cov}\left(R_{j}^{e}, R_{M k t}^{e}\right) / \sigma_{M k t}^{2} \\
(t \text {-stat) }\end{array}$ & $\begin{array}{r}1.08 \\
(8.08)\end{array}$ & $\begin{array}{r}0.87 \\
(5.28)\end{array}$ & $\begin{array}{r}1.06 \\
(11.30)\end{array}$ & $\begin{array}{r}0.88 \\
(5.43)\end{array}$ & $\begin{array}{r}0.97 \\
(7.53)\end{array}$ & $\begin{array}{r}0.11 \\
(0.56)\end{array}$ \\
\hline $\begin{array}{l}\operatorname{Cov}\left(R_{j}^{e}, R_{I M C}^{e}\right) / \sigma_{I M C}^{2} \\
(t \text {-stat) }\end{array}$ & $\begin{array}{r}-0.07 \\
(-0.27)\end{array}$ & $\begin{array}{r}-0.17 \\
(-1.09)\end{array}$ & $\begin{array}{r}0.16 \\
(0.92)\end{array}$ & $\begin{array}{r}0.19 \\
(1.14)\end{array}$ & $\begin{array}{r}0.36 \\
(2.88)\end{array}$ & $\begin{array}{r}-0.43 \\
(-2.53)\end{array}$ \\
\hline $\begin{array}{l}\operatorname{Cov}\left(R_{j}^{e}, z^{\xi}\right) / \sigma_{z}^{2} \\
(t \text {-stat })\end{array}$ & $\begin{array}{r}-2.26 \\
(-1.05)\end{array}$ & $\begin{array}{r}-3.99 \\
(-1.59)\end{array}$ & $\begin{array}{r}-2.20 \\
(-0.96)\end{array}$ & $\begin{array}{r}-1.71 \\
(-0.84)\end{array}$ & $\begin{array}{r}-0.37 \\
(-0.18)\end{array}$ & $\begin{array}{r}-1.90 \\
(-1.22)\end{array}$ \\
\hline
\end{tabular}

Table 9: Commodity futures portfolio risk exposure (univariate beta) to the commodity market and investment shocks. The commodity market factor is constructed as the equally weighted commodity futures across commodities and maturities in the sample. I use two proxies of investment shocks. The $I M C$ factor is defined as the stock portfolio excess return of investment good relative to consumption good producers. The other proxy is the relative price of investment $\xi$ from Israelsen (2010), who extends the quality-adjusted price series of Gordon (1990) to 2008. Innovations $z_{t}^{\xi}$ is defined as $\log \xi_{t}=a_{0} t+a_{1} t \mathbf{1}_{\{t>1982\}}+\rho \log \xi_{t-1}-z_{t}^{\xi}$. Panel A reports the univariate betas of the full sample. Panel B reports the univariate betas of a subsample of the same set of commodities from 1985 to 2008. The $t$-stats are reported in parentheses and are adjusted using a Newey-West correction. 


\begin{tabular}{crl}
\hline \hline Parameter & Value & Description \\
\hline Technology & & \\
$\delta$ & 0.01 & Monthly capital depreciation rate \\
$\eta$ & 3 & Aggregate price elasticity of commodity demand \\
$\theta$ & 12 & Slope parameter in the monthly capital adjustment cost
\end{tabular}

\section{Exogenous shock \\ $\begin{array}{lll}\rho_{y} & 0.92 & \text { Persistence of investment shock }\end{array}$ \\ $\begin{array}{lll}\sigma_{y} & 0.03 \quad \text { Conditional volatility of investment shock }\end{array}$ \\ $\mu_{x} \quad 0.042 \quad$ Average monthly growth rate of aggregate demand (\%) \\ $\sigma_{x} \quad 0.008 \quad$ Monthly volatility of aggregate demand shock \\ $\sigma_{z} \quad 0.06 \quad$ Monthly volatility of idiosyncratic demand shock}

\section{Stochastic discount factor}

\begin{tabular}{crl}
$r_{f}$ & 0.33 & Monthly real risk-free rate (\%) \\
$\gamma_{x}$ & 1 & Risk price of aggregate demand shock \\
$\gamma_{y}$ & -12 & Risk price of investment shock \\
\hline \hline
\end{tabular}

Table 10: Parameter values of the benchmark model

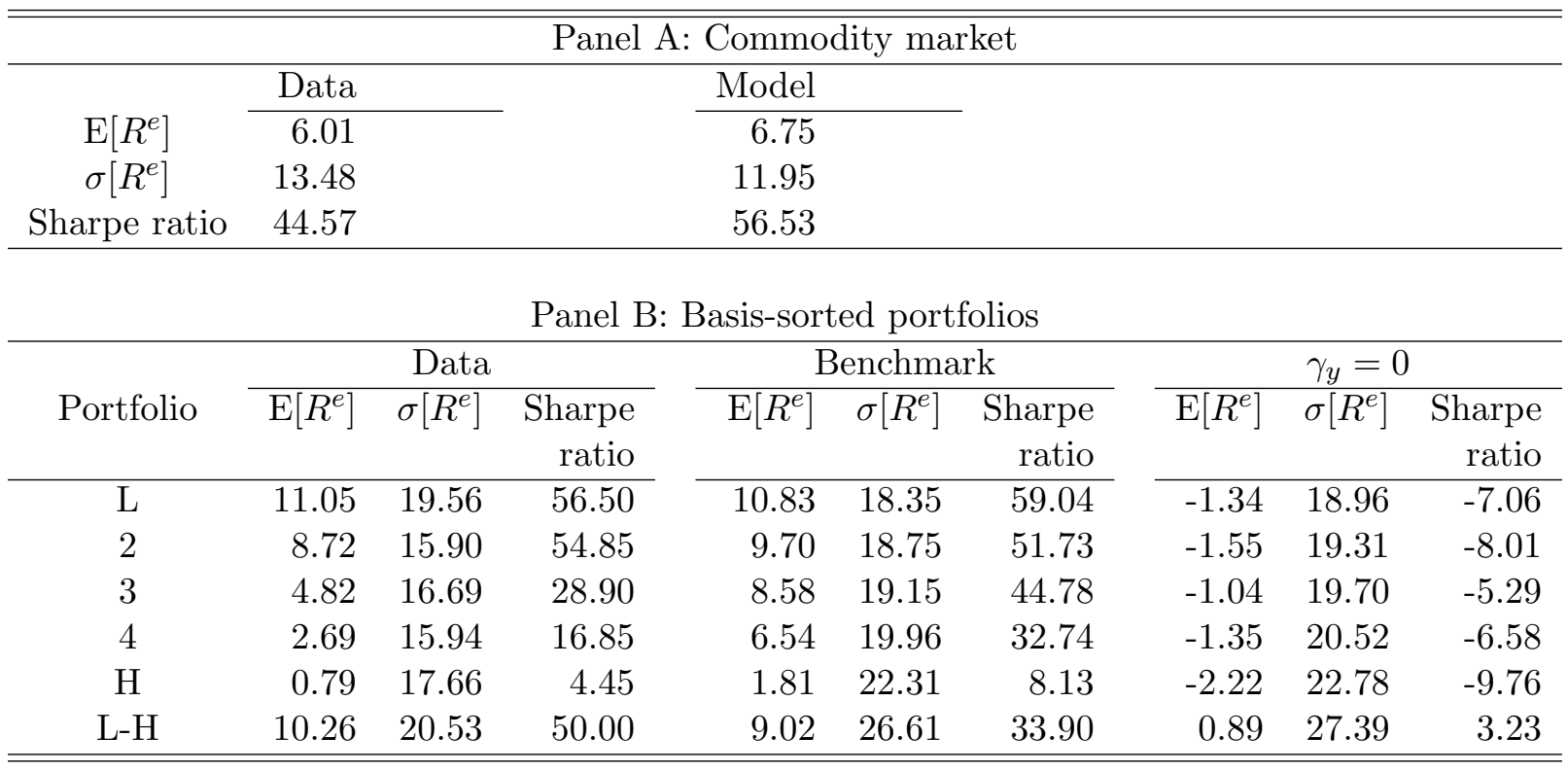

Table 11: Model-simulated moments of commodity futures market and basis-sorted portfolios. Panel A compares the commodity market expected excess return $\left(\mathrm{E}\left[R^{e}\right]\right)$, volatility $\left(\sigma\left[R^{e}\right]\right)$, and Sharpe ratio in both real and simulated data. Panel B compares the average excess returns $\left(\mathrm{E}\left[R^{e}\right]\right)$, volatilities $\left(\sigma\left[R^{e}\right]\right)$, and Sharpe ratios of the five portfolios sorted by basis and L-H portfolio from real and simulated data from the benchmark model and $\gamma_{y}=0$. 


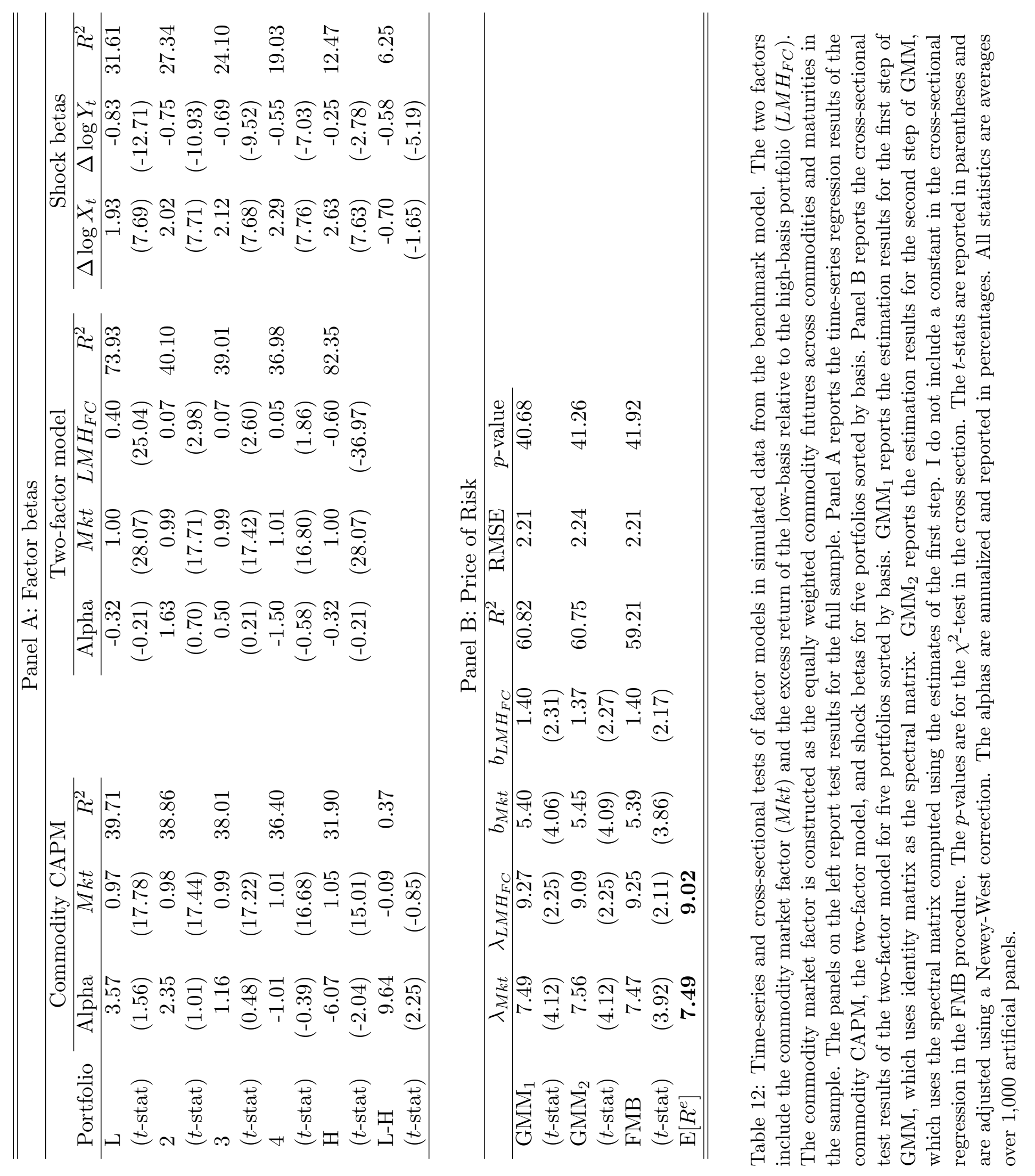




\begin{tabular}{|c|c|c|c|c|c|c|}
\hline Portfolio & $\overline{\mathrm{L}}$ & 2 & 3 & $\overline{4}$ & $\overline{\mathrm{H}}$ & $\overline{\mathrm{L}-\mathrm{H}}$ \\
\hline & \multicolumn{6}{|c|}{ Data } \\
\hline $\mathrm{E}\left[R^{e}\right]$ & 11.05 & 8.72 & 4.82 & 2.69 & 0.79 & 10.26 \\
\hline \multirow[t]{2}{*}{$\sigma\left[R^{e}\right]$} & 19.56 & 15.90 & 16.69 & 15.94 & 17.66 & 20.53 \\
\hline & \multicolumn{6}{|c|}{ Benchmark } \\
\hline $\mathrm{E}\left[R^{e}\right]$ & 10.83 & 9.70 & 8.58 & 6.54 & 1.81 & 9.02 \\
\hline \multirow[t]{2}{*}{$\sigma\left[R^{e}\right]$} & 18.35 & 18.75 & 19.15 & 19.96 & 22.31 & 26.61 \\
\hline & \multicolumn{6}{|c|}{ No irreversibility constraint } \\
\hline $\mathrm{E}\left[R^{e}\right]$ & 10.95 & 9.67 & 9.48 & 8.34 & 7.34 & 3.61 \\
\hline \multirow[t]{2}{*}{$\sigma\left[R^{e}\right]$} & 18.59 & 18.96 & 19.25 & 19.53 & 20.07 & 23.53 \\
\hline & \multicolumn{6}{|c|}{$\theta=6$} \\
\hline $\mathrm{E}\left[R^{e}\right]$ & 14.29 & 13.06 & 11.88 & 8.79 & 2.44 & 11.85 \\
\hline \multirow[t]{2}{*}{$\sigma\left[R^{e}\right]$} & 18.09 & 18.30 & 18.58 & 19.40 & 22.30 & 26.26 \\
\hline & \multicolumn{6}{|c|}{$\theta=24$} \\
\hline $\mathrm{E}\left[R^{e}\right]$ & 7.98 & 6.46 & 5.96 & 4.94 & 1.81 & 6.17 \\
\hline$\sigma\left[R^{e}\right]$ & 19.22 & 19.69 & 20.08 & 20.64 & 22.50 & 27.39 \\
\hline
\end{tabular}

Table 13: The sensitivity of the basis spread to investment frictions of commodity producers. $\theta$ is the monthly slope parameters in capital adjustment costs.

\begin{tabular}{lrrrrrr}
\hline \hline & Low & 1 & 2 & 3 & High & L-H \\
\hline Alpha & 11.03 & 8.47 & 4.38 & 2.18 & 0.26 & 10.78 \\
(t-stat) & $(2.99)$ & $(2.75)$ & $(1.49)$ & $(0.81)$ & $(0.09)$ & $(3.16)$ \\
& & & & & & \\
$M k t$ & 0.00 & 0.06 & 0.10 & 0.11 & 0.12 & -0.11 \\
(t-stat) & $(0.05)$ & $(0.74)$ & $(1.37)$ & $(1.93)$ & $(1.62)$ & $(-1.66)$ \\
& & & & & & \\
$R^{2}(\%)$ & 0.00 & 0.33 & 0.89 & 1.29 & 1.13 & 0.78 \\
\hline \hline
\end{tabular}

Table 14: Time-series tests of the standard CAPM. The market factor is the value-weighted excess return on all NYSE, AMEX, and NASDAQ stocks (from CRSP). The sample includes monthly close quotes of futures of maturities up to 12 months of 34 commodities from January 1970 to December 2008. The $t$-stats are reported in parentheses and are adjusted using a Newey-West correction. 


\begin{tabular}{lrrrrrr}
\hline \hline & Low & 1 & 2 & 3 & High & L-H \\
\hline Alpha & 10.51 & 7.31 & 3.54 & 1.22 & -0.88 & 11.39 \\
(t-stat) & $(2.76)$ & $(2.26)$ & $(1.10)$ & $(0.45)$ & $(-0.31)$ & $(3.20)$ \\
& & & & & & \\
$M k t$ & -0.02 & 0.08 & 0.13 & 0.13 & 0.13 & -0.14 \\
(t-stat) & $(-0.16)$ & $(0.97)$ & $(1.58)$ & $(2.07)$ & $(1.62)$ & $(-1.86)$ \\
& & & & & & \\
$S M B$ & 0.17 & 0.08 & 0.00 & 0.08 & 0.15 & 0.02 \\
(t-stat) & $(1.74)$ & $(1.09)$ & $(0.04)$ & $(1.11)$ & $(1.61)$ & $(0.21)$ \\
& & & & & & \\
$H M L$ & 0.05 & 0.16 & 0.12 & 0.13 & 0.15 & -0.10 \\
(t-stat) & $(0.43)$ & $(1.78)$ & $(1.28)$ & $(1.63)$ & $(1.40)$ & $(-0.93)$ \\
$R^{2}(\%)$ & 0.86 & 1.34 & 1.39 & 2.01 & 2.29 & 1.01 \\
\hline \hline
\end{tabular}

Table 15: Time-series tests of Fama-French three-factor model (Fama and French (1992)). The sample includes monthly close quotes of futures of maturities up to 12 months of 34 commodities from January 1970 to December 2008. The $t$-stats are reported in parentheses and are adjusted using a Newey-West correction.

\begin{tabular}{lrrrrrr}
\hline \hline & Low & 1 & 2 & 3 & High & L-H \\
\hline $\begin{array}{l}\text { Alpha } \\
\text { (t-stat) }\end{array}$ & 9.05 & 6.16 & 3.56 & 1.40 & 0.20 & 8.85 \\
& & $(1.81)$ & $(1.01)$ & $(0.48)$ & $(0.07)$ & $(2.41)$ \\
$M k t$ & 0.00 & 0.10 & 0.13 & 0.13 & 0.11 & -0.11 \\
(t-stat) & $(0.03)$ & $(1.12)$ & $(1.52)$ & $(1.96)$ & $(1.48)$ & $(-1.46)$ \\
& & & & & & \\
SMB & 0.17 & 0.08 & 0.00 & 0.08 & 0.15 & 0.03 \\
(t-stat) & $(1.78)$ & $(1.16)$ & $(0.04)$ & $(1.12)$ & $(1.66)$ & $(0.30)$ \\
& & & & & & \\
HML & 0.08 & 0.19 & 0.12 & 0.13 & 0.12 & -0.04 \\
(t-stat) & $(0.70)$ & $(1.96)$ & $(1.21)$ & $(1.57)$ & $(1.17)$ & $(-0.38)$ \\
& & & & & & \\
$M O M$ & 0.12 & 0.09 & 0.00 & -0.01 & -0.09 & 0.20 \\
(t-stat) & $(1.45)$ & $(1.33)$ & $(-0.03)$ & $(-0.26)$ & $(-1.43)$ & $(2.64)$ \\
$R^{2}(\%)$ & 1.57 & 2.00 & 1.39 & 2.02 & 2.77 & 2.97 \\
\hline \hline
\end{tabular}

Table 16: Time-series tests of Carhart four-factor model (Carhart (1997)). The sample includes monthly close quotes of futures of maturities up to 12 months of 34 commodities from January 1970 to December 2008. The $t$-stats are reported in parentheses and are adjusted using a Newey-West correction. 

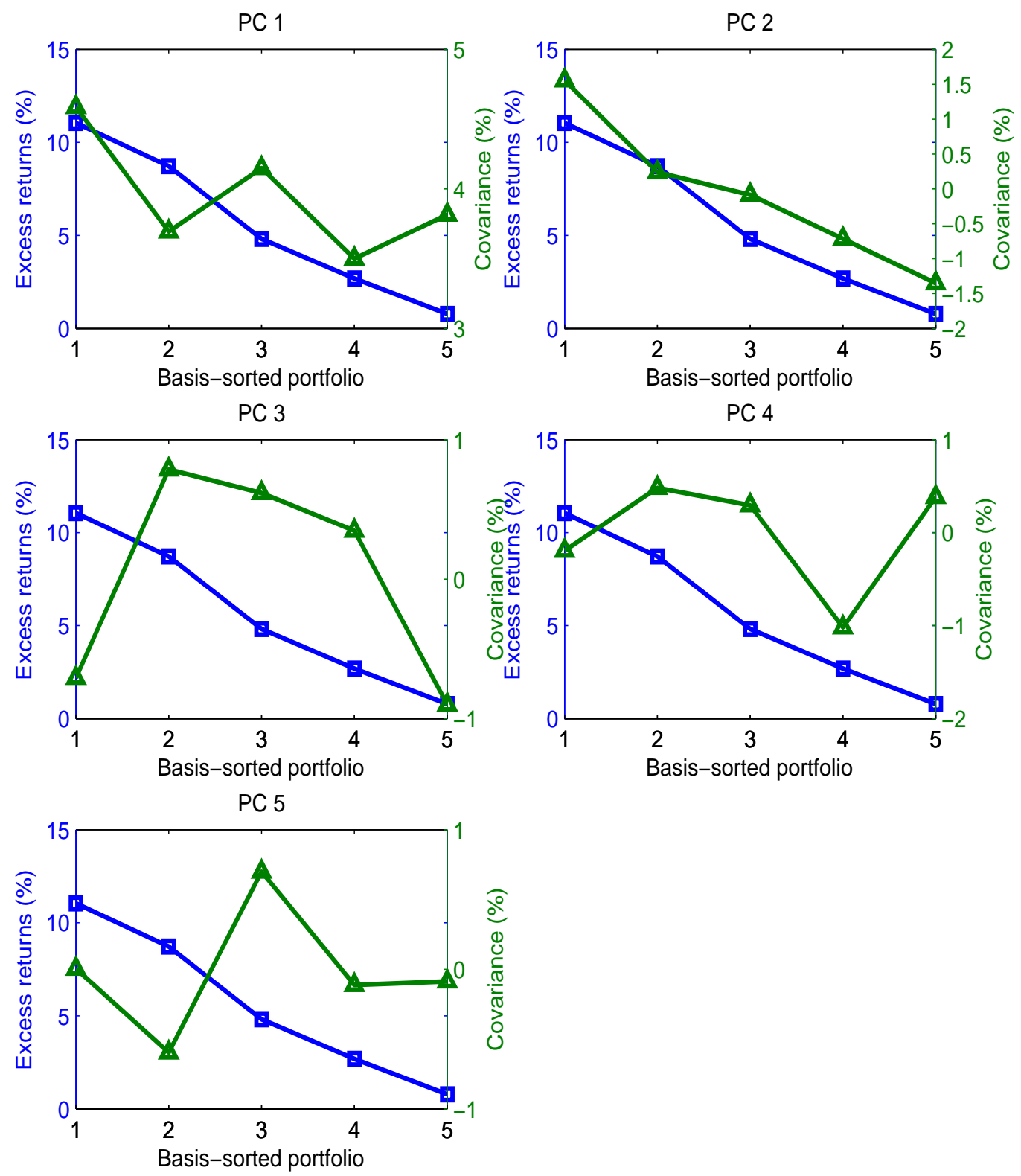

Figure 1: Average excess returns (triangle) of five portfolios sorted by basis and covariances (square) between five portfolio excess returns and each principal component. 

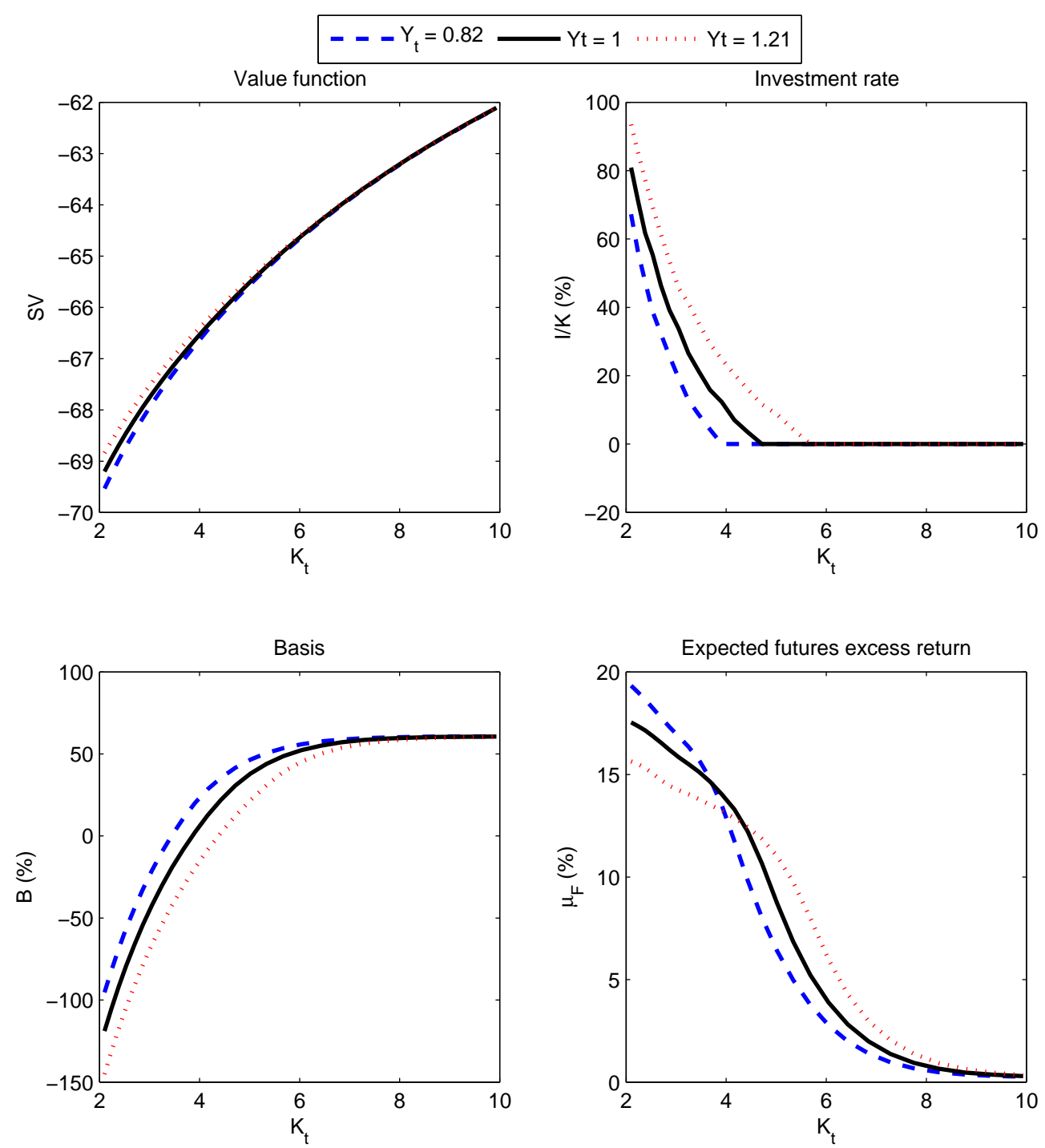

Figure 2: Value and policy functions of investment rate, basis, and expected futures excess return of the benchmark model. Basis is computed as the difference between log 12-month futures price and log spot price. Expected futures excess return is the expected excess return of longing 12-month futures for one month. The dashed curves (blue) represent the functions when investment shock $Y_{t}=0.82$. The smooth curves (black) represent the functions when investment shock $Y_{t}=1$. The dotted curves (red) represent the functions when investment shock $Y_{t}=1.21$. Policy functions are annualized. 


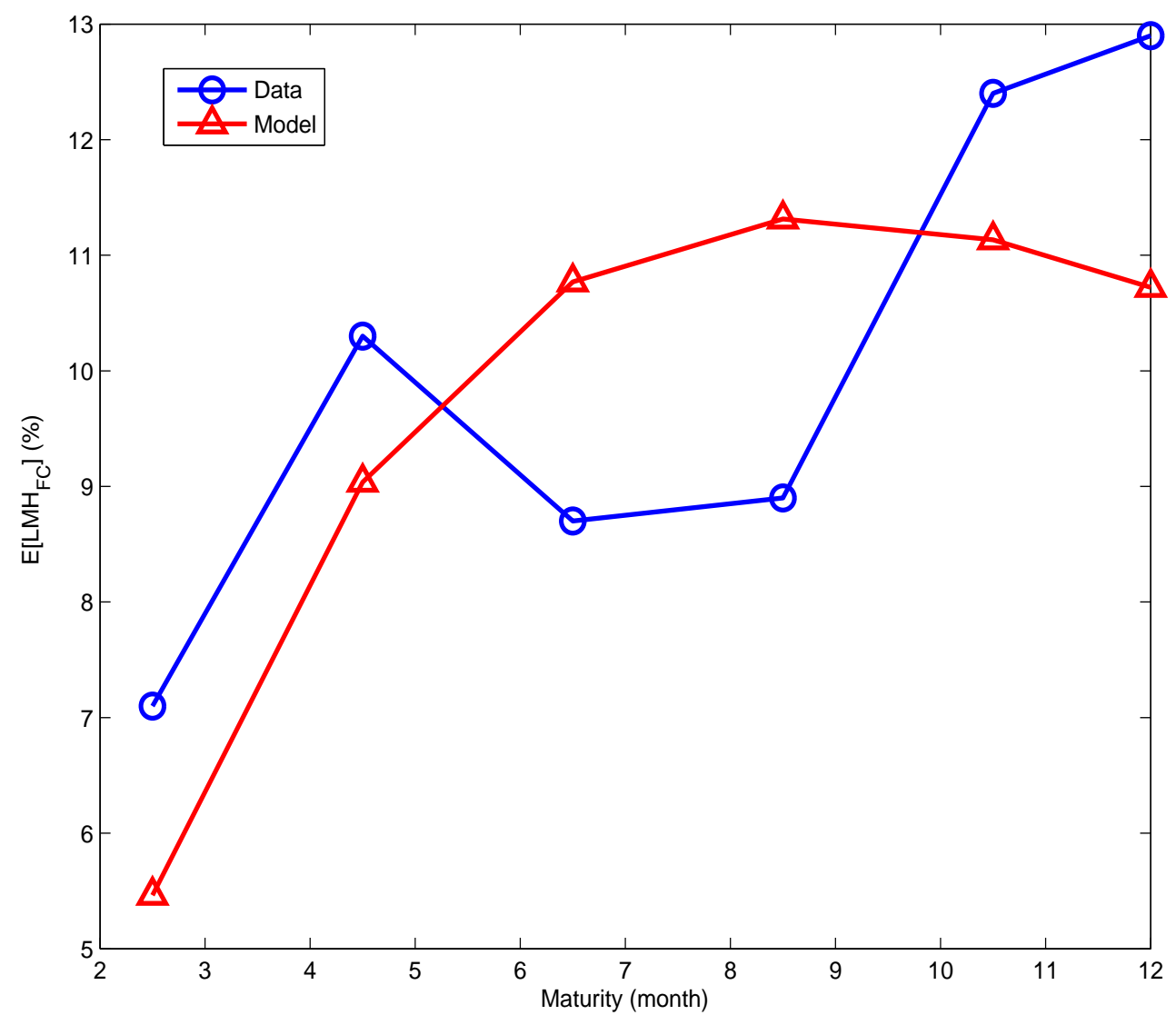

Figure 3: Term structure of the basis spread. The curve marked with circles (blue) represents real data. The curve marked with triangles (blue) represents model-simulated data. 